\title{
Die Handschrift des Stadtschreibers Heinrich Polan als Beispiel der Verwendung der neugotischen Schrift in der Kanzlei der mährischen Stadt Olmütz
}

\begin{abstract}
Zarys treści: Autor wskazuje na możliwość przedostawania się wzorców pisma neogotyckiego na Morawy z północy, analizując styl pisma Heinricha Polana — gdańszczanina, który po okresie pracy w śląskiej Nysie został pisarzem miejskim w Ołomuńcu.

Abstract: The author shows the opportunity of spreading of the neo-gothic-style writing from the North to Moravia. This hypothesis is based on the analysis of the style of handwriting of Heinrich Polan - city writer of Olomouc, born in Gdańsk, who worked many years in Nysa before his stay in Moravia.
\end{abstract}

Słowa kluczowe: Neografia, rękopis neogotycki, analiza paleograficzna, Olomuniec, Śląsk, pisarz miejski.

Keywords: Paleography of the early Modern Times, neo-Gothic handwriting, paleographical analysis, Olomouc, Olmütz, Silesia, city scribe.

Das wesentlichste Merkmal der Entwicklung der lateinischen Schrift in der Neuzeit war die Teilung des bisher einheitlichen Schriftstils des späten Mittelalters in einen humanistischen und neugotischen Zweig. Beide grundlegenden Stile der neuzeitlichen Periode der Schriftentwicklung, der neugotische und der humanistische, existierten lange Zeit nebeneinander, beeinflussten sich gegenseitig und konkurrierten miteinander. Die humanistische Schrift wurde zuerst vor allem in lateinischen Texten verwendet. Bereits mit Beginn des 16. Jahrhunderts kann man jedoch auf dem gesamten Gebiet der lateinischen Schrifttradition einen Prozess verfolgen, in dem diese Schrift allmählich die neugotische Schrift verdrängte. Dieser Prozess verlief jedoch nicht überall gleich schnell und die neugotische Schrift erhielt sich lange ihre Dominanz. In verschiedenen Gebieten traten in der Entwicklung der neuzeitlichen Schrift jedoch örtliche Besonderheiten auf, die auch im Mitteleuropa der ersten Hälfte des 16. Jahrhunderts spezifische Züge annahmen. ${ }^{1}$

Die deutsche neugotische ${ }^{2}$ Schrift entwickelte sich in all ihren Arten und Varianten und dominierte vor allem in den deutschsprachigen Gebieten. In Böhmen und Mähren stellte die heimische Schrifttradition, die

\footnotetext{
1 J. Kašpar, Úvod do novověké latinské paleografie se zvláštním zřetelem k českým zemím, 1. svazek-Textová část. Praha ${ }^{3} 1987$, S. 48; J. Kašpar, K problematice novověké latinské paleografie (II.), in: Dvě stě let pomocných věd historických na Filozofické fakultě Karlovy univerzity v Praze, Praha 1988, S. 230.

2 Die in der tschechischen Paläographie gängige und etablierte Bezeichnung „,novogotické písmo [,,neugotische Schrift”] wird in dieser Form auch ins Deutsche übersetzt. (Z.B.J. Kašpar, $K$ problematice vzniku a vývoje německé novogotické kurzívy. (Na okraj studií Tamary N. Tacenkové a Friedricha Becka), in: 2, „Z pomocných věd historických” 8, Praha 1988, S. 120, die deutsche Zusammenfassung auf der Seite „Acta Universitatis Carolinae, Philosophica et historica” [weiter: AUC-PhilosHist] 131. Mit diesem Terminus werden Schriften bezeichnet, die sich vom Beginn des 16. Jahrhunderts an auf
} 
aus der böhmischen spätmittelalterlichen Halbkursive hervorging, welche die Entstehung einer böhmischen neugotischen Schrift ermöglichte, einen bedeutenden Impuls der Schriftentwicklung dar. Einen zweiten Impuls der Schriftentwicklung stellt eine Gruppe von entwickelten Typen der neugotischen Schrift dar, die auf verschiedenen Wegen aus den deutschen Ländern kamen. Die Adjektiva „deutsch” und „böhmisch” leiten sich in diesen Bezeichnungen von den Gestaltungen der zugehörigen Schrift ab, keinesfalls nur von der Sprache des Textes, in der sie verwendet wurde oder vom Territorium ihrer Verbreitung. Die humanistische Schrift breitete sich nach Mitteleuropa nicht nur direkt von Italien, sondern auch über Ungarn aus, wo sie sich vor allem am Königshof entwickelte. Im polnischen Königreich entwickelte sich die nationale neugotische Schrift vor allem in kursiver Form, welche allmählich Kurrentelemente annahm. Unter dem Einfluss der Renaissance kam hier auch die humanistische Schrift zur Geltung, die nicht nur an lateinische Texte gebunden war und die schon in den 30er Jahren des 16. Jahrhunderts die ältere Form der gotisch-humanistischen Schrift verdrängte. Im benachbarten Schlesien dominierte die deutsche neugotische Schrift. Neben der Übernahme von Mustern aus den deutschen Schreibschulen zeigte die dortige neugotische Schrift jedoch auch eine zu einer unabhängigen Schriftgestaltung neigende Tendenz. ${ }^{3}$

Bei der Untersuchung der neuzeitlichen lateinischen Schrift, besonders in der Anfangsperiode ihrer vom Beginn des 16. Jahrhunderts bis zum Beginn des 17. Jahrhunderts dauernden Entwicklung, spielen die Kanzleien bedeutender Urheber eine wichtige Rolle. Die Mobilität der Dokumente als Träger neuer Arten der lateinischen Schrift zwischen verschiedenen administrativen Zentren stellt ein wichtiges, jedoch aus Sicht der Paläographie der Neuzeit ${ }^{4}$ bisher ungenutztes Forschungsthema dar. ${ }^{5}$

der Basis der mittelalterlichen gotischen Schrift herausgebildet haben. Den Terminus verwendete als erster der dänische Paläograph Erik Kroman in Form von „nygotisk Skrift” (Skriftens Historie i Danmark fra Reformationen til Nutiden, Kobenhavn 1943, ${ }^{2}$ Viborg 1964). In der deutschen Literatur werden solche Schriften gewöhnlich mit dem zusammenfassenden und unbestimmten Begriff „Deutsche Schrift” oder mit den traditionellen Begriffen Kurrentschrift, Kanzleischrift und Frakturschrift u. a. bezeichnet. Der Ausdruck „,neugotische Schrift” wird mit der Begründung abgelehnt, dass die Bezeichnung der neugotischen künstlerischen Stil vom Ende des 18. Jahrhunderts unzulässig auf die gesamte neuzeitliche Entwicklungsperiode übertragen wird. (F. Beck, Zur Herausbildung der deutschen Schreibschrift, insbesondere ihrer kursiven Formen, im Gebiet ostdeutscher Territorialstaaten im 16. Jahrhundert, in: „Jahrbuch für Geschichte der Feudalismus” 7 , 1983, S. 268-269; A. Gieysztor, Zarys dziejow pisma lacińskiego. Warszawa 1973, S. 187). Zu den angegebenen Einwänden betont J. Kašpar, dass die Bezeichnung „neugotische Schrift” von der Bezeichnung „gotische Schrift” als paläographischem Terminus abgeleitet wird, nicht von der Bezeichnung der allgemeinen neugotischen künstlerischen Stil (J. Kašpar, Úvaha o paleografické terminologii, AUC-PhilosHist. 4-5, 1987, „Z pomocných věd historických” 6-7, S. 22). In der polnischen Paläographie begegnen wir in diesem Zusammenhang auch dem Terminus ,pismo postgotyckie”, die ins Deutsche als ,nachgotische Schrift” übersetzt wird. (J. Słowiński: Rozwój pisma łacińskiego w Polsce XVI-XVIII wieku, Lublin 1992, S. 51).

${ }^{3}$ I. Hlaváček, J. Kašpar, R. Nový, Vademecum pomocných věd historických, Praha ${ }^{3} 2002$, S. 91; K. Dülfer, H.E. Korn, Schrifttafeln zur deutschen Paläographie des 16.-20. Jahrhunderts, bearbeitet von K. Uhde, Marburg ${ }^{10} 1998$, S. 12f.; J. Kašpar, Novogotické písmo v Čechách v letech 1500-1750, in: AUC-PhilosHist, 3-4, 1971, S. 111 und weiter; K. Bobowski, Ewolucja pisma neogotyckiego na Ślasku od poczatku XVI do polowy XX wieku, Wrocław - Warszawa 1992, S. 37 und weiter; J. Słowiński, Rozwój, S. 51 und weiter, S. 70 und weiter; Od gotiky k renesanci. Výtvarná kultura Moravy a Slezska 1400-1550. III. Olomoucko, (red.) I. Hlobil - M. Perůtka, Olomouc 1999, S. 48-50.

${ }^{4}$ In der tschechischen paläographischen Terminologie wird für die Disziplin, die als integralen Bestandteil der lateinischen Paläographie die neuzeitliche lateinische Schrift untersucht, die Bezeichnung „Novověká latinská paleografie” [„Neuzeitliche lateinische Paläographie"] verwendet. Diese Terminologie führte der Pionier ihrer Erforschung Jaroslav Kašpar ein. (J. Kašpar, Úvod do novovéké latinské paleografie se zvláštním zřetelem k českým zemím. 1. sv., S. 5f.; J. Kašpar: Názvosloví novověkých písem, in: J. Kašpar, Soubor statí o novověkém písmu, Praha 1993, S. 59-98). In unserem Aufsatz verwenden wir eine Bezeichnung, die dem tschechischen Terminus nahesteht und gleichzeitig im deutschsprachigen Raum bekannt ist - Paläographie der Neuzeit (L. Santifaller: Bozner Schreibschriften der Neuzeit 1500-1851. Beiträge zur Paläographie. Jena 1930, S. 3-4). In der Gegenwart verwenden die deutschen Paläographen für die Disziplin, die die neuzeitliche Epoche der lateinischen Schriftentwicklung erforscht, freilich eher den Ausdruck „Schriftkunde” (F. Beck, Zur Herausbildung der deutschen Schreibschrift, insbesondere ihrer kursiven Formen, im Gebiet ostdeutscher Territorialstaaten im 16. Jahrhundert, in: „Jahrbuch für Geschichte der Feudalismus” 7, 1983, S. 271). In der polnischen Paläographie begegnen wir im Zusammenhang mit dieser Disziplin meistens dem Terminus „,neografia” (K. Górski, Neografia gotycka. Podręcznik pisma neogotyckiego XVI-XX w., Warszawa ${ }^{3} 1978$ ).

5 J. Kašpar, Příspěvek $k$ metodice výzkumu novověkého psaného písma v Čechách. Problematika evidence psaného písma, in: AUC-PhilosHist. 5, 1980, „Z pomocných věd historických” 4, S. 79. 
Die Fluktuation dieser amtlichen Dokumente musste jedoch nicht der einzige Weg der Verbreitung in der Frühen Neuzeit sein. Als Multiplikatoren der neuen Schriftformen, also Vermittler der Schrifttransformation aus anderen Gebieten, können unter bestimmten Bedingungen auch einzelne Schreiber angesehen werden. Eine solche Identifizierung bedürfte jedoch des Beweises, dass der Schreiber in eine bestimmte Kanzlei bereits mit einer etablierten Handschrift eingetreten ist, die dann Kennzeichen der neuen Schriftart aufweist. Gleichzeitig müsste bekannt sein, aus welchem Gebiet der Schreiber an seine neue Wirkungsstätte kam. Dann wäre es nach unserer Meinung möglich, die Hypothese aufzustellen, dass dieser Schreiber die Kanzleipraxis um eine neue Schriftart bereichert hat und zugleich dass er die Kenntnis dieser Schriftart in dem Gebiet erlangen konnte, woher er kam.

Ein typisches Beispiel eines bedeutenden administrativen Zentrums im Sinne des in dieser Studie erwähnten Modells, ist die Königsstadt Olmütz. Olmütz gehört im 16. Jahrhundert zusammen mit Brünn zu den Hauptverwaltungs- und -wirtschaftszentren der Markgrafschaft Mähren. ${ }^{6}$ Diese Stellung von Olmütz als wichtiger Knotenpunkt politischer, wirtschaftlicher und kultureller Einflüsse hatte zur Folge, dass sie in den historischen Quellen Olmützer Provenienz einige Momente der Schriftentwicklung zeigten, die im einleitenden Teil der Studie beschrieben wurden. Nicht nur die Ausweitung der mit der Entwicklung von Olmütz verbundenen städtischen Verwaltung ${ }^{7}$, sondern auch die Aufrechterhaltung der amtlichen Kommunikation mit den herrschaftlichen Kanzleien in Ofen / Buda, in Prag und in Wien einerseits, und die schriftliche Beziehung mit dem schlesischen Breslau als Hauptstadt des Magdeburger Rechts auf der anderen Seite ${ }^{8}$, stellen nur einen Teil der Gründe dar, die zum Anwachsen des Verwaltungsapparats und damit auch zur Entwicklung der Olmützer Stadtkanzlei beitrugen. ${ }^{9}$

Nicht nur durch die gebildeten Beamten stellte die Olmützer Stadtkanzlei eine wichtige Institution dar, sondern hier trafen und kreuzten sich auch neue kulturelle Anregungen. Neben dem Wirken des Humanismus, der für das Olmütz der Frührenaissance typisch war ${ }^{10}$, setzten sich in der Stadtkanzlei allmählich auch ästhetische Prinzipien des neugotischen Stils durch. Diese Prinzipien zeigten sich vor allem in der Schriftkultur, welche eine Modernisierung ihrer Formen und eine neue analytischsynthetische Methode ihrer Lehre beinhaltete. ${ }^{11}$

Die Anfänge der deutschen neugotischen Schrift in der Olmützer Stadtkanzlei sind eng verbunden mit der Abschrift eines Schreibmusterbuches, welches vor allem Muster der neugotischen Schrift enthält. Es handelte sich um Muster, die in ihrer Zeit einerseits eine für die Epoche typische Art der Schreiblehre demonstrierten und andererseits neue Arten der Schrift ausländischer Herkunft, aus der deutschen Umgebung aufzeigten. Die erwähnte Abschrift dieses Schreiblehrwerks erwarb einer der gelehrten Olmützer Stadtschreiber mit europäischem Horizont wohl ungefähr im ersten Jahrzehnt des 16. Jahrhunderts. Aus dem Inhalt des Lehrwerks geht hervor, dass der Schreiber Christof Lindensperger aus Passau wohl den Archetyp gestaltet haben könnte. Wenn die Olmützer Abschrift aus dem ersten Jahrzehnt des 16. Jahrhunderts kommt, musste ihr Archetyp sogar noch früher entstanden sein als das erste Schreibmusterbuch aus Nürnberg, das für die Entwicklung der neugotischen Schrift den entscheidenden Impuls setzte! Das älteste von ihnen wurde nämlich erst im Jahre 1519 herausgegeben. ${ }^{12}$

\footnotetext{
${ }_{6}^{6}$ J. Schulz und andere, Dějiny Olomouce, 1. Bd., Olomouc, Statutární město Olomouc a Univerzita Palackého v Olomouci, 2009, S. 278; V. Nešpor, Dějiny Olomouce, Brno 1936, S. 92-95, 142-146.

7 J. Kux, Verwaltungsgeschichte der Stadt Olmütz, Olmütz 1942, S. 83.

8 V. Spáčil, Sbírka listin archivu města Olomouce 1261-1793. Inventár̆, Olomouc 1998, S. 417-421; Die Rechtliche Hinweise und die Urteile von Breslau nach Olomouc gegeben 1484-1565, SOkA Olomouc, AMO, Bücher, sign. 6671, inv. č. 90a; B. Kaňák, Tajemství olomouckých městských knih, Olomouc 2014, S. 45-46, 67.

9 V. Spáčil, Písaři a kanceláre mésta Olomouce do roku 1786, Olomouc 2001, S. 72 und weiter.

${ }^{10}$ I. Hlobil, E. Petrů, Humanismus a raná renesance na Moravě, Praha 1992, S. 31.

11 J. Schulz und andere, Olomouc. Malé dějiny města, Olomouc 2002, S. 91.

12 J. Kašpar, Učebnice psaní Christofa Lindenspergera z počátku šestnáctého století, in: AUC-PhilosHist 1, „Z pomocných věd historických" 3, Praha 1975, S. 105 und weiter; A. Kapr, Johann Neudörffer der Ältere, der grosse Schreibmeister der deutschen Renaissance, Leipzig 1956, S. 22.
} 
Weil die erwähnte Abschrift dieses Lehrwerks der damals modernen Schrift integraler Bestandteil eines der Olmützer Stadtbücher ist, kann man mit großer Wahrscheinlichkeit davon ausgehen, dass gerade die Schriftmuster, die in dieser Abschrift enthalten sind, das Interesse der städtischen Beamten für die deutsche neugotische Kursive und v.a. für die deutsche neugotische Halbkursive weckten. ${ }^{13}$ Das Interesse für die angeführten Schriftmuster war so stark, dass einer der jüngeren Aushilfsschreiber schon in der ersten Hälfte der 20er Jahre des 16. Jahrhunderts auf Basis des Lehrwerksmusters einen eigenen Typus der halbkursiven Schrift entwickelte, die er zusammen mit der neugotischen Kursive in seiner Schreibpraxis zur Geltung brachte. ${ }^{14}$

Der Prozess des Eindringens neuer Muster in das Olmützer Milieu wurde dann in der zweiten Hälfte der 30er Jahre des 16. Jahrhunderts noch um einige Schreibtypen des humanistischen Stils bereichert. Auch zu diesem Prozess trug die angeführte Abschrift des Schreiblehrwerks bei, da es neben der Schrift neugotischen Stils auch Beispiele von Minuskeln der humanistischen gezeichneten Schrift, Minuskeln der humanistischen Halbkursive und Majuskeln der Quadratkapitale des humanistischen Stils enthielt. Die Olmützer Abschrift des Schreiblehrwerks gilt sogar als erste bekannte Quelle ihrer Art nördlich der Alpen mit Mustern der humanistischen Schrift! In der untersuchten Zeit überwog in der Olmützer Schreibproduktion jedoch die Schrift im neugotischen Stil eindeutig gegenüber dem humanistischen Stil. ${ }^{15}$

Als eine der markanten Erscheinungen der lateinischen Schrift zu Beginn ihrer neuzeitlichen Periode kann man die Variabilität der Formen der Schrift in neugotischem Stil ansehen. Neben der gezeichneten Schrift entwickelten sich im Anfangsstadium der Entwicklung der neugotischen Schrift ihre verschiedenen kursiven und halbkursiven Schriftformen. Die Schreiber, die im deutschsprachigen Raum die neugotische Schrift veredelten, richteten ihr Augenmerk von der Gestaltung ihrer Stilkaligraphie hin zur Konzeption eines Klassifikationssystems der Schriftarten. Dank ihrer Bemühungen können wir drei Hauptarten der deutschen neugotischen Schrift mit traditionellen Bezeichnungen unterscheiden: Fraktur, Kurrent und Kanzlei. ${ }^{16}$

$\mathrm{Zu}$ Beginn der frühen Neuzeit transformierte sich die kaligraphische halbkursive Schrift des 15. Jahrhunderts zur deutschen neugotischen gezeichneten Schrift, welche die traditionelle Bezeichnung „Frakturschrift” trägt. Als deutsche neugotische gezeichnete Schrift klassifizieren wir alle Formen von Schrift, die mit einer Feder mit breiter Spitze gestaltet ist. Die einzelnen Grapheme sind in der Regel viel größer als die gewöhnlich geschriebenen Schriftarten, die sich aus einer größeren Anzahl von Schattenstrichen zusammensetzen, ihre Achse ist vertikal und ihre Schäfte sind fett. Die Majuskeln der gezeichneten Schrift haben zahlreiche Varianten und ihre verzierten Teile zerschlagen häufig den Grundduktus der Buchstaben, wenn sie das Übermaß ihrer Kaligraphie betonen. ${ }^{17}$

Die am häufigsten verwendete Art der deutschen neugotischen Schrift war die Kursive, traditionell als Kurrentschrift bezeichnet. Das Wesen der neuzeitlichen Kursive rührte allgemein von der Bemühung um einen schnelleren, flüssigeren und einfacheren schriftlichen Ausdruck her. Dieser Prozess beschleunigte sich bei häufigem Schreiben und vertiefte sich durch die unterbewusste Automatisierung der Schriftgestaltung. Die Art der Verbindung der einzelnen Buchstaben zu einem Ganzen, so dass sie kontinuierlich geschrieben werden konnten, führte zur Entwicklung der kursiven Ausrichtung des Federzuges. Sein Kern war die Perfektionierung der Anknüpfung der Schreibstriche, welche die Grundgestalt eines jeden Buchstaben bildete. Gleichzeitig entwickelten sich auch

${ }^{13}$ B. Kaňák, Paleografická edice opisu učebnice psaní pocházejicího z počátku 16. století z Olomouce, Olomouc 2008, S. 7-8, 15 .

${ }_{14}$ B. Kaňák, Paleografická edice, S. 72-74.

15 J. Kašpar, Učebnice psaní, S. 112-114; B. Kaňák, Tajemství olomouckých městských knih, S. 77.

${ }^{16}$ K. Górski, Neografia gotycka, S. 16-18; I. Hlaváček, J. Kašpar, R. Nový, Vademecum, S. 76-80; J. Kašpar, Názvosloví, S. 63.

17 J. Kašpar, Úvod do novověké latinské paleografie, S. 43, 52; K. Schneider, Paläographie — Handschriftenkunde, Tübingen 1999, S. 81-82. 
Verbindungsstriche, die eine flüssige Verbindung der Buchstaben mit den benachbarten Graphemen im Wort ermöglichten. ${ }^{18}$

Der halbkursive Charakter der letzten erwähnten Hauptgattung der deutschen neugotischen Schrift war vor allem durch die Vereinfachung des Duktus der einzelnen gezeichneten Buchstaben gegeben, die jedoch immer noch aus mehreren Strichen zusammengesetzt waren, sowie durch die Andeutung der Verbindung dieser Buchstaben im Wort. Diese Verbindung wurde gleichzeitig größtenteils nicht vollendet. Ein weiteres typisches Merkmal der deutschen neugotischen Halbkursive, die traditionell Kanzleischrift genannt wird, ist die überwiegende vertikale Achse der Buchstaben, die jedoch auch eine Neigung einiger Schäfte nach rechts und links nicht ausschließt, besonders im anfänglichen Entwicklungsstadium. Der Duktus der deutschen neugotischen Halbkursive ist einfacher als bei der gezeichneten Schrift, jedoch komplizierter und dekorativer als bei der Kursivschrift, was v.a. für die Majuskeln gilt. ${ }^{19}$

$\mathrm{Zu}$ den wesentlichen allgemeinen Zügen der späteren reifen neugotischen Schrift gehört, wie allgemein bekannt ist, die Winkelbindung. Die frühe deutsche neugotische Kursivschrift, die ab den 20er Jahren des 16. Jahrhunderts in Olmütz verwendet wurde, zeichnete sich jedoch paradoxerweise durch die Abwesenheit der Winkelbindung aus. In der Abschrift des Lehrwerks wurde die neugotische Kursivschrift direkt mit dem unterscheidenden Typenattribut als „gewölbt” bezeichnet. ${ }^{20}$ Seit den 30er Jahren des 16. Jahrhunderts kam jedoch eine weitere Generation von Olmützer Schreibern zur Geltung, welche eine ausgeprägtere Form der deutschen neugotischen Schrift verwendete, die sich bereits durch eine unübersehbare Winkelbindung auszeichnete. ${ }^{21}$

Unter den Olmützer Schreibern dieser Zeit sticht durch seine markante Handschrift Heinrich Polan hervor, dessen schriftlicher Ausdruck Hauptgegenstand der Analyse in dieser Studie ist. Auf Grundlage der Arbeit seines Biographen Josef Zukal können wir schon zu Beginn der Analyse festhalten, dass Heinrich Polan eines der Kriterien erfüllt, die wir als Eigenschaften eines Schreibers, der die neuen Schreibformen verbreitete, bezeichnet haben, also seine Rolle als Vermittler des Schrifttransfers aus einem anderen Gebiet. Der in Danzig geborene Polan war Pole, er war evangelisch und verweilte eine gewisse Zeit vor seiner Ankunft in Olmütz in der schlesischen Stadt Neiße. ${ }^{22}$ Obwohl F. Č́da, der sich mit Polans juristischem Werk beschäftigt hat, die Behauptung Zukals über Polans Studium in Krakau anzweifelt oder die Vermutungen weiterer Forscher über sein Studium in Breslau oder sogar in Wittenberg ${ }^{23}$, ändert dies nichts an der Tatsache, dass er nach Olmütz aus einem Gebiet kam, das von der Dominanz der deutschen neugotischen Schrift gekennzeichnet war. ${ }^{24}$ Gelingt es uns, Polans Schrift mit einer paläographischen Analyse genauer zu klassifizieren und die Entwicklung seiner Handschrift seit seiner Ankunft in Olmütz zu erfassen, dann können wir nach unserer Prämisse auch die Hypothese erhärten, dass er die Kenntnis dieser Schrift aus seinem früheren vorübergehenden Aufenthaltsort mitbrachte.

\footnotetext{
18 J. Kašpar, Úvod do novověké latinské paleografie, S. 42, 52-53; F. Beck, Zur Herausbildung der deutschen Schreibschrift, insbesondere ihrer kursiven Formen, im Gebiet ostdeutscher Territorialstaaten im 16. Jahrhundert, 277-278.

19 J. Kašpar, Úvod do novověké latinské paleografie, S. 43, 52; B. Kaňák, Německá novogotická polokurziva (kanzlei) olomoucké městské kanceláre v 16.-19. století, in: „Ročenka Státního okresního archivu v Olomouci” 8, 1999, S. 46.

${ }^{20} \mathrm{Zu}$ den bisher nicht gelösten Problemen der Entwicklung der neugotischen Schrift gehört die Frage, warum die Schrift mit dem Charakteristikum ,gewölbt” erst im Leitfaden des Nürnberger Schreibers Wolfgang Fugger aus dem Jahr 1553 auftaucht! B. Kaňák, Paleografická edice, S. 10, 18.

${ }^{21}$ J. Kux, Verwaltungsgeschichte, Schriftproben aus den städtischen Handschriften und Akten, S. VII; B. Kaňák, Tajemství olomouckých městských knih, S. 105.

22 J. Zukal, Polanové z Polansdorfu. Památná rodina opavská 16. věku, in: „Časopis Matice moravské” [weiter: ČMM] 51, 1927, S. 100-104.

${ }^{23}$ F. Čáda, Polský rodák a městské právo v Olomouci a v Opavě, in: „Česko-polský sborník” I, 1955, S. 279-280; M. Radlinský (Das Pseudonym von Vinzenz Prasek), Vynikající osoby opavské z 16. století, in: „Věstník Matice opavské” 4, 1894, S. 27; J. Zukal, Polanové z Polansdorfu, S. 100.

${ }^{24}$ K. Bobowski, Ewolucja, S. 37 und weiter.
} 
Der älteste Nachweis für die Schreiberhand Polans in den amtlichen Dokumenten der Olmützer städtischen Provinienz sind Aufzeichnungen, die in die Zeit vom 10. November 1539 bis zum Jahr 1547 datieren, wo er nach und nach die Raten für ein Haus eintrug, welche der Olmützer Bürger Wilhelm Krohmer zahlte. Man kann jedoch nicht ausschließen, dass es sich dabei teilweise um Zusatzeinträge handelt. ${ }^{25}$ Josef Zukal, der der Familie Polan eine spezielle Studie gewidmet hat ${ }^{26}$, datiert zwar Heinrichs Ankunft in Olmütz erst auf das Jahr 1547, als Polan sich in amtlichen Einträgen bereits selbst mit dem offiziellen Titel ,Scheppenschreiber” bezeichnete ${ }^{27}$, jedoch belegte Vladmir Spáčil in seiner umfangreichen Arbeit über die Olmützer Schreiber seinen Aufenthalt in Olmütz bereits mindestens um zwei Jahre früher und erinnerte gleichzeitig an Polans private öffentliche Anwaltspraxis (notarius publicus). ${ }^{28}$

Aus einer Reihe von Dokumenten, in denen Heinrich die Spur seiner Schrift hinterließ, wählen wir für die hiesigen Bedürfnisse der Studie eine der Aufzeichnungen im Gerichtsprotokoll der strittigen und unstrittigen Zivilangelegenheiten aus den Jahren 1548-1549 aus, welche gänzlich von ihm vorgenommen wurde..$^{29}$ An diesem Protokoll kann man auch Polans innovative administrative Vorgehensweise belegen, weil er in das Buch gleichzeitig mit den Einträgen auch ein Register einführte, das nach den Taufnamen der Personen geführt wurde, die bei der Eintragung der Rechtsakte beteiligt war. ${ }^{30}$

Das größte Werk von Heinrich sind die Rechtsartikel des Olmützer städtischen Gerichts, eine praktische Handreichung des Magdeburger Rechts aus dem Jahr 1550, das eine Prozessordnung für städtische Gerichtsverfahren enthielt, die sich auch auf einige weitere mährische Städte erstreckte. ${ }^{31}$ Der Bedeutung des Inhalts entspricht auch die Kaligraphie des Autors, von der wir für die Bedürfnisse unserer paläographischen Analyse die Titelseite und einen Teil der Einleitung auswählen. ${ }^{32}$ Eine weitere schriftliche Quelle, die eine exemplarische Schriftprobe von Heinrichs Kaligraphie enthält, ist das Titelblatt des Zeugnisbuches vor dem anhängigen städtischen Gericht ebenfalls aus dem Jahr 1550.33

Am 17. Juni des Jahres 1551 entschied der Bürgermeister zusammen mit allen drei Stadträten der Stadt Olmütz über die definitive Aufnahme von Heinrich Polan als „scheppenschreiber und gerichtsschreiber". Nach dieser Entscheidung blieb Polan jedoch nicht lange in seinem Amt, da er bereits am 19. Oktober des Jahres 1552 seine Tätigkeit als Gerichtsschreiber in Olmütz beendete. J. Zukal stellte sich die Frage, warum Heinrich Polan Olmütz verließ, wo es ihm gut ging und wo er sich ein Bürgerhaus gekauft hatte, und er kam zum Schluss, dass wohl seine Sehnsucht nach einem höheren und einflussreicheren Rang entschied. Ein solches Amt gab es fraglos in Gestalt des Syndikus, also eines leitenden Stadtschreibers, der selbst eher die Funktion eines Rechtsberaters des Stadtrats erfüllte und zur eigenen Erfüllung der Amtsagenda eine Reihe von untergeordneten Beamten hatte. ${ }^{34}$ Um Heinrichs schriftliche Äußerung vom Ende seiner Wirkungszeit in Olmütz darzulegen, schließen wir die Sammlung seiner ausgewählten Schriftproben mit einer Aufzeichnung im Buch der Urteile des anhängigen städtischen Gerichts aus dem Jahre 1552. ${ }^{35}$

In unserer Arbeit haben wir bereits erwähnt, dass für die Handschrift Heinrich Polans eine ausgeprägtere Form der deutschen neugotischen Schrift typisch war, die sich bereits durch eine

\footnotetext{
${ }^{25}$ V. Spáčil, Písaři, S. 306, pozn. 16. Siehe auch die 6. Schriftprobe in der Beilage unserer Arbeit.

26 J. Zukal, Polanové z Polansdorfu, S. 101.

${ }^{27}$ Inventar der Verlassenschaften von den Stadtbürgern (Inventarium), 1522-1564, SOkA Olomouc, AMO, Bücher, sign. 120, inv. č. 2017, f. 32r, Eintrag von dem 28. Juli 1547.

${ }^{28}$ V. Spáčil, Písaři, S. 306, pozn. 16, 21.

${ }^{29}$ Siehe die 7. Schriftprobe aus dem Jahre 1548 in der Beilage unserer Arbeit.

${ }^{30}$ V. Spáčil, Písaři, S. 307.

31 J. Zukal, Polanové z Polansdorfu, S. 101; V. Spáčil, Písaři, S. 308; die ältere Edition des Handbuchs von A. Fischel (Die Olmützer Gerichtsordnung. Ein Beitrag zur Geschichte des österreichischen Prozessrechtes, Brünn 1903), führt Polan als Verfasser noch nicht an und hält das Handbuch für ein anonymes Werk.

32 Siehe die 8. und die 9. Schriftprobe in der Beilage unserer Arbeit.

33 SOkA Olomouc, AMO, Bücher, sign. 189, inv. č. 2046. Siehe die 10. Schriftprobe in der Beilage unserer Arbeit.

${ }^{34}$ J. Zukal, Polanové z Polansdorfu, S. 102; V. Spáčil, Písaři, S. 74-75.

35 SOkA Olomouc, AMO, Bücher, sign. 198, inv. č. 2037. Siehe die 11. Schriftprobe in der Beilage unserer Arbeit.
} 
unübersehbare Winkelbindung auszeichnete. Dieses Merkmal von einer Dominanz der Winkelbindung verbindet Polans Handschrift mit dem Werk des Nürnberger Schreibemeister Johann Neudörffer des Älteren, der mit Recht als bedeutender Schöpfer von einem Muster der deutschen neugotischen Schrift angesehen wird. In der Literatur wird die Gruppe seiner Schüler und Fortsetzer daher als Nürnberger Schreibschule bezeichnet. ${ }^{36}$ Wenn wir davon ausgehen, dass die Neigung einiger Olmützer Schreiber zur Winkelbindung in ihrer Kenntnis der Schrift der Nürnberger Schreibschule begründet ist und wenn wir vergleichendes paläographisches Material zur Bestätigung der angeführten Annahme suchen, dann finden wir die typischste Ausprägung dieser Schrift vom Ende der 30er Jahre des 16. Jahrhunderts im Schreiblehrwerk von Johann Neudörffer des Älteren aus dem Jahre 1538 „Ein gute ordnung, und kurtze unterricht, der furnemsten grunde ..." ${ }^{\text {37 }}$

Die Schriftanalyse dieses Lehrwerks stellt jedoch ein beachtliches Problem dar, das v.a. der breiten Skala von Formen der in ihr dargestellten Schrift geschuldet ist. ${ }^{38}$ Und dieses bei einer gleichzeitigen Beschränkung des erklärenden Autorentextes auf das kleinstmögliche Minimum. ${ }^{39}$ Das Lehrwerk unterteilt zwar die Formen der einzelnen Buchstaben systematisch in sechs grundlegende Gruppen nach den überwiegenden gemeinsamen Zeichen (,superfities” d. h. superficies), führt die Schüler zur Zusammenstellung der Buchstaben mit Hilfe typisierter Grundgestaltungen und zeigt verschiedene Schriftvarianten nach der Stufe des verzierten Durchbruchs oder der unterschiedlichen Neigung, jedoch bietet es noch kein einheitliches Klassifikationsschema der deutschen neugotischen Schrift. ${ }^{40}$ Ein solches Klassifikationssystem bringt erst ,Ein nutzlich vnd wolgegrundt formular, manncherley schöner schriefften ...“, ein Lehrwerk ${ }^{41}$ von Neudörffers Schüler Wolfgang Fugger aus dem Jahr 1553, was jedoch bereits über den zeitlichen Horizont unserer Untersuchung hinausgeht. Eine weitere Klippe bringen die verschiedenen sich in Zahl und Anordnung der Druckseiten unterscheidenden Überlieferungsvarianten von Neudörffers Lehrwerk, welche über eine Reihe von deutschen und österreichischen Museen und Bibliotheken verstreut sind. ${ }^{42}$ Wir nehmen jedoch an, dass für die Suche eines gewissen Maßes an Analogie zwischen der Schrift von Heinrich Polan und Johann Neudörffer ein einziges relativ gut erhaltenes Exemplar des Nürnberger Lehrwerks aus dem Jahr 1538, das wir in digitaler Fassung auf den Internetseiten der Bayerischen Staatsbibliothek in München gefunden haben, genügen wird. ${ }^{43}$

Das Hauptproblem beim Finden passender Muster besteht in der Tatsache, dass man in Neudörffers Lehrbuch praktisch keine Schriftprobe finden kann, die vom Autor selbst gleichzeitig direkt mit den späteren traditionellen Typenbezeichungen der deutschen neugotischen Schrift als Kurrent oder Kanzlei bezeichnet wäre. Nachweislich wird hier nur die Bezeichnung „fractur” verwendet. ${ }^{44}$ Aus der Vielzahl der in Neudörffers Lehrwerk enthaltenen Varianten haben wir deshalb für die Bedürfnisse

${ }^{36}$ W. Doede, Schön schreiben, eine Kunst. Johann Neudörffer und seine Schule im 16. und 17. Jahrhundert, München 1957, S. 21; K. Górski, Neografia gotycka, S. 16; J. Kašpar, K problematice vzniku a vývoje německé novogotické kurzivy. (Na okraj studií Tamary N. Tacenkové a Friedricha Becka), Praha 1988, S. 119 und weiter; J. Kašpar, Norimberská písařská škola Johanna Neudörffera staršího a její vliv v českých zemích, in: Historia docet. Sborník prací k poctě 60. narozenin prof. PhDr. Ivana Hlaváčka, Praha 1992, S. 135 und weiter.

${ }^{37}$ Die vollständige Bezeichnung, die wir aus Platzspargründen nicht in vollem Umfang zitieren, weil sie sehr lange ist, führt

W. Doede an (Bibliographie deutscher Schreibmeisterbücher von Neudörffer bis 1800, Hamburg 1961, S. 38-39).

38 J. Kašpar, Úvod do novověké latinské paleografie, S. 31.

39 W. Doede, Schön schreiben, eine Kunst, S. 21.

${ }^{40}$ Neudörffer verwendet in seinen Kommentaren sehr selten die Bezeichnung „fractur” für die deutsche neugotische gezeichnete Schrift und für die anderen Schriftarten gebraucht er meistens unadressierte Begriffe wie „buchstaben” oder „schrift".

${ }_{41}$ W. Doede, Bibliographie, S. 46; W. Fugger, Ein nutzlich und wolgegrundt formular, manncherley schöner schriefften, ... 1553, Nürnberg, Vědecká knihovna v Olomouci (Die wissenschaftliche Bibliothek in Olomouc) [weiter: VKOl], (Die historischen Sammlungen), Sign. 602105, besonders Pag. 18-19, 22, 45, 50, 52.

${ }^{42}$ W. Doede, Bibliographie, S. 38-39.

${ }^{43}$ BSB München, AHAD, sign. Chalc. 18 a (VD16 N 563). Wir geben die persistenteren Web-Links, die auf den veröffentlichten Reproduktionen der relevanten Quellen beziehen, in der endgültigen Liste der Quellen und Literatur an.

${ }^{44}$ BSB München, AHAD, sign. Chalc. 18 a, f. 11. 
unseres Vergleichs eine eigene Auswahl vorgenommen. Dabei haben wir die ausgewählten Gruppen der Grapheme aus der Retrospektive der späteren Entwicklung der neugotischen Schrift betrachtet und solche ausgesucht, die man als Anfangsstadium der Kursive, der gezeichneten Schrift und der halbkursiven Schrift nach den allgemein bekannten Charakteristiken dieser Schriftarten klassifizieren kann. ${ }^{45}$ Unsere Auswahl richtete sich weiter nach der Bedingung, dass die Muster eine gewisse abgerundete Textsammlung bilden und dass sie gleichzeitig einen im Verhältnis zur Lesbarkeit der Grapheme reproduzierbaren Umfang haben.

Wir haben also das Muster der alphabetischen Reihe gewählt, die sich durch eine einfache kursive Ausrichtung des Federzuges auszeichnet, deren Flüchtigkeit durch eine Neigung nach rechts verstärkt wird ${ }^{46}$, oder die Schrifttabelle, die halbkursive Elemente aufweist — besonders verschiedene Neigungen der Schäfte in einem Buchstabensatz und die verzierende Ausrichtung des Federzugs, die sich besonders im bogenförmigen Durchbrechen der Köpfe der letzten Bögen der Minuskeln -mund -n- zeigt. ${ }^{47}$ Einen halbkursiven Charakter hat auch der dritte von Neudörffer ausgewählte Text, in dem ein weiteres Merkmal der Kanzleischrift deutlich wird, die Existenz von Verbindungsstrichen einzelner Grapheme, deren Funktion jedoch in einer Reihe von Fällen nicht realisiert wird, weil zwischen den Buchstaben verschiedene kleine Lücken bleiben. ${ }^{48}$ Ein weiteres Muster aus unserer Auswahl enthält eine Reihe von Majuskeln der deutschen neugotischen Schrift, die ihre einfacheren und komplizierteren Formen darstellen. Einfachere Formen gehören eher zur Kursivschrift oder Halbkursivschrift, die verzierteren Formen kommen in der Fraktur zur Geltung. An dieser Stelle ist es jedoch angebracht festzuhalten, dass Majuskeln aller Arten in der deutschen neugotischen Schrift besonders in der frühen Entwicklungszeit den gezeichneten Formen näher standen. ${ }^{49}$ Das letzte Muster Neudörffers stellt die Fraktur als zusammenhängenden Text und als alphabetische Reihe der Minuskeln dar. $\mathrm{Zu}$ seinen typischen Merkmalen gehören besonders die vertikalen Achsen der Buchstaben, eine ausgeprägte Schattierung, getrennte Grapheme und eine einfache oder zweifache Brechung der Striche. ${ }^{50}$ Die ausgewählten beschriebenen Schriftproben von Neudörffers Schrift präsentieren wir zusammen mit den bereits erwähnten handschriftlichen Texten von Heinrich Polan einerseits in der Form von elf nummerierten Schriftproben in der Anlage, andererseits in Form von zwei abschließend zusammenfassende Vergleichstabellen der Minuskeln und Majuskeln. Bei allen Schriftproben ist eine kommentierte paläographische Transliteration vorgenommen worden. ${ }^{51}$ Damit die Konkordanz zwischen den zusammenfassenden Tafeln und den nummerierten Schriftproben sichergestellt ist, sind alle Grapheme, die aus den zu untersuchenden Texten ausgewählt wurde und in die Tabellen aufgenommen wurden, in der Transliteration fettgedruckt.

Die Tabelle I. enthält die Sammlungen der Minuskeln und ist in einer solchen Weise angeordnet, dass in den Spalten 1-3 die ausgewählten Grapheme der Neudörffer'schen Schrift eingereiht sind, die der Kursivschrift (1), der halbkursiven Schrift (2) und der gezeichneten Schrift—Fraktur (3) entsprechen. In die Spalten 4-6 sind dann die analogen und differenten Grapheme Heinrich Polans, die sich in kongruente

\footnotetext{
45 Absichtlich verwenden wir die vorsichtige Bezeichnung „halbkursive Schrift”, da in der Zeit der Herausgabe des Lehrwerks im Jahre 1538 die deutsche neugotische Halbkursive (Kanzleischrift) noch nicht ausgeprägt war. B. Kaňák, Německá novogotická polokurzíva (kanzlei), S. 45.

${ }^{46}$ BSB München, AHAD, sign. Chalc. 18 a, f. 40. Siehe auch die 1. Schriftprobe in der Beilage unserer Arbeit.

47 BSB München, AHAD, sign. Chalc. 18 a, f. 27. Siehe auch die 2. Schriftprobe in der Beilage unserer Arbeit. Zur Problematik der halbkursiven Elemente - B. Kaňák, Německá novogotická polokurziva (kanzlei), S. 51-52.

${ }^{48}$ BSB München, AHAD, sign. Chalc. 18 a, f. 34. Siehe auch die 3. Schriftprobe in der Beilage unserer Arbeit. Zur Funktion der Verbindungslinien - K. Dülfer, H.E. Korn, Schrifttafeln zur deutschen Paläographie, S. 17.

49 BSB München, AHAD, sign. Chalc. 18 a, f. 10. Siehe auch die 4. Schriftprobe in der Beilage unserer Arbeit. Zum Eigenart der Majuskeln - W. Doede, Bibliographie, S. 6.

${ }^{50}$ BSB München, AHAD, sign. Chalc. 18 a, f. 52. Siehe auch die 5. Schriftprobe in der Beilage unserer Arbeit. Zum Eigenart der Fraktur - J. Kašpar, Úvod do novověké latinské paleografie, S. 52.

${ }^{51}$ Wir befolgen die von J. Kašpar zusammengefaßte Grundsätze der paläographischen Beschreibung in Úvod do novověké latinské paleografie, S. 10-12.
} 
Gruppen in derselben Reihenfolge gliedern, eingereiht. Die Tabelle II. ist auf ähnliche Weise erarbeitet, analysiert jedoch in den untersuchten Schriftproben die Majuskeln. Weil wir strikt von den edierten Schriftproben ausgehen, deren Dimensionen durch die Publikationsmöglichkeiten begrenzt sind, fehlen uns die Muster einiger Majuskeln aus der Schrift von Polan. Die Suche nach passenden Exemplaren aller Majuskeln bedürfte einer wesentlich größeren Quellenbasis, welche hier nicht geleistet werden kann. Unsere abschließende Modellanalyse ${ }^{52}$ von Neudörffers Musterschrift und Polans Handschrift fußt v.a. auf den beiden Vergleichstabellen (I., II.), die schon für sich selbst einen interessanten Aussagewert haben.

Zunächst wenden wir uns den Minuskeln der ersten Tabelle zu. Der Grundduktus aller hier aufgeführten Grapheme der deutschen neugotischen Kursive (Spalten 1 und 4) ist sehr ähnlich, was auf den ersten Blick ersichtlich wird. Es handelt sich um eine schattierte Schrift mit einer leichten Neigung nach rechts, die verbunden geschrieben wird, mit Gewicht, die dem Anfangsstadium der Kursive angepasst ist, und einem Modul, in welchem die vertikale Streckung und eine geringere Breite überwiegen. In beiden Spalten finden wir die Varianten -b-, -d- und - $h$ - mit Schlinge im oberen Bereich und einem einfachen Schaft. Polan verwendete mehrere Schlingen bei den langen Buchstaben im oberen Bereich auch mit einfachem Schaft, wie bei -l- ersichtlich wird. Im Falle der Minuskel -hfinden wir bei ihr sogar auch eine progressive kursive Variante mit einer direkten Verbindung der oberen und niederen Schlinge..$^{53}$ Polan unterscheidet sich von Neudörffer vornehmlich in der Variante -g-. In Polans Graphem wird zunächst im mittleren Band ein Ballen gebildet, zu dem sich dann eine Schlinge anschließt, die sich zum oberen Bereich ausrichtet. Neudörffer schafft zuerst eine Schleife, zu der er dann im mittleren Bereich einen eckigen Ballen hinzufügt, der nach rechts gerichtet ist. Neudörffer verwendet auch -r-, in dem der Doppelschaft noch verwächst, während Polan bereits das progressive kursive -r- schreibt, in dem der Doppelschaft noch auf der Grundlinie durch eine kleine Arkade verbunden ist. Die gemeinsamen Merkmale überwiegen jedoch gegenüber den Unterschieden.

Eine Analogie finden wir auch in der halbkursiven Schrift (Spalte 2 und 5). Es handelt sich um eine schattierte Schrift eher vertikalen Charakters, die jedoch einige deutlich nach rechts geneigte Schäfte aufweist (z. B. -c-, -m-, -n-, -v-, -w-). Sie zeichnet sich durch ziemlich entwickelte Anschlüsse aus, die sie nicht konsequent verbindet, und durch ein Modul, dessen vertikale Streckung jedoch nicht so groß ist wie im Falle der Kursivschrift. In beiden Spalten finden wir bereits ein größeres Maß an Stilisierung, welche im Bogendurchbruch der Köpfe der letzten Bögen -m- und -n- ersichtlich wird. Neudörffer hat mehrere Varianten der Grapheme (-d-, -g-, -h-, -x-, -z-), aus denen einige die Kursive nachahmen, was bei der Undeutlichkeit dieser Schriftart in der untersuchten Zeit bemerkenswert ist. Gemeinsame Züge des Duktus von Polan und Neudörffer überwiegen auch hier gegenüber den Unterschieden.

Eine fraglose Ähnlichkeit weist auch die Fraktur (Spalte 3 und 6) auf. Dies ist in beiden Fällen eine schattierte Vertikale, die bei Neudörffer in der Reihe der Grapheme auch Varianten mit zweifachem Umbruch (-a-, -m-, -n-, -o-) hat. Dieses Element, das aus Neudöffers gebrochener Schrift hervorgeht, finden wir in einem Fall auch bei Polan (-a-). In beiden Spalten registrieren wir auch eine Durchbrechung der Köpfe der letzten Bögen -m- und -n-. Polan hat in seiner Fraktur im Vergleich zu Neudörffer mehr Buchstaben, die im oberen Bereich mit Schleifen oder ihren Andeutungen beendet sind (-b-, -h-, -k-, -1-). Mit Neudörffers Schrift hat er jedoch eine analoge Endung des oberen Bogens der Minuskel. Die beobachtete Schrift hat in beiden Fällen ein größeres Gewicht und ein breiteres Modul als die vorhergehenden Arten, was jedoch für die Fraktur in der untersuchten Zeit typisch ist. Die gemeinsamen Merkmale überwiegen also ebenfalls.

An dieser Stelle ist es nötig, in einem kleinen Exkurs ein terminologisches Problem zu präzisieren. Die tschechische Fachliteratur betonte bisher das Moment der zweifach gebrochenen Schäfte als

\footnotetext{
${ }^{52}$ Bei der Transliteration folgen wir vor allem den von Z. Hledíková, J. Kašpar und I. Ebelová formulierten Prinzipien in der Veröffentlichung in Paleografická čítanka, Praha 2000, S. 6 und weiter.

${ }_{53}$ Vergleiche die Varianten des Minuskels -h- zum Beispiel mit der Arbeit von I. Ebelová, Klíč k novověké paleografii. Schlüssel zur neuzeitlichen Paläographie, Praha 2004, S. 22.
} 
typisches Zeichen des embryonalen Stadiums der deutschen neugotischen Halbkursive (Kanzlei), die sie als Neudörffer`sche gebrochene Schrift interpretierte. ${ }^{54}$ Wir gehen jedoch von einer größeren Verbreitung dieses Moments aus, das gut bemerkbar in einem späteren Lehrwerk des NeudörfferSchülers Wolfgang Fugger ist, wo die zweifache Brechung nicht nur in einigen Varianten der Kanzleischrift verbreitet ist, sondern auch als dekoratives Element eines Typs der Fraktur. ${ }^{55}$ Neudörffer selbst verbindet im Kommentar zu seinem Lehrwerk aus dem Jahr 1538 die Charakteristik „gebrochen” in der neugotischen Schrift nicht nur mit der Schrift des halbkursiven Duktus, sondern interpretiert sie nach unserem Urteil im Rahmen des allgemeinen Schaffensprinzips der neugotischen gezeichneten Schrift, die auch Fraktur enthält, als seine beste Schaffensphase. Weil die Schriftprobe der neugotischen gezeichneten Schrift, die wir aus dem Lehrwerk Neudörffers als Vergleichsmaterial ausgewählt haben, auch die erwähnte Variante der zweifachen Brechung aufweist, führen auch wir diese Brechung in unserer Arbeit im Zusammenhang mit der Fraktur an. Aus unserer Schriftprobe wird deutlich, dass sich die zweifache Brechung nicht auf die Schäfte beschränkt, sondern dass in den relevanten Graphemen zum Beispiel auch die Bogenstriche zweifach gebrochen sind. ${ }^{56}$

Als letztes kommen die Majuskeln in der Tabelle II an die Reihe. Hier bewegen wir uns auf dünnerem Eis als in den vorhergehenden Analysen, weil Neudörffer die Majuskeln getrennt von den Minuskeln meist ohne jeglichen erklärenden Kommentar in einer zusammenhängenden Tabelle darstellt. Ihre Zugehörigkeit zu den einzelnen Arten der deutschen neugotischen Schrift ist also hypothetisch und stützt sich hauptsächlich auf unsere Erfahrung mit der praktischen Verwendung dieser Buchstaben und auf ein größeres oder kleineres Maß der Einfachheit ihres Duktus oder den Pomp ihrer Zierstriche. Wir gehen von der Voraussetzung aus, dass die Kursivschrift den einfachsten Duktus hat; die meisten Verzierungen und die komplizierteste Ausrichtung des Bogenstrichs hat die Fraktur. Die halbkursiven Formen der Majuskeln stehen irgendwo zwischen diesen beiden Polen.

Eine Reihe von Majuskeln, die für die Kursivschrift verwendbar sind (Spalte 1 und 4) hat z. B. übereinstimmende Wesensmerkmale im Falle des Graphems -A- mit deutlich kursivem Duktus. Dieses Graphem wurde durch die Vergrößerung der einfachen Minuskel -a- gebildet. ${ }^{57}$ Eine größere oder kleinere Kongruenz sehen wir auch im Duktus der Grapheme -B-, -E-, -G-, -H-, -I-, -O-, -P-, -S-, -T-, -Z-. Bei Neudörffer haben die untersuchten Majuskeln außer -A- jedoch einen vertikalen Charakter, während Polan in einer Reihe von Fällen die Vergrößerungen der Minuskeln mit einer merklichen Linksneigung (-D-) oder Rechtsneigung (-K-, -M-, -N-) verwendet. Die Majuskeln sind überwiegend deutlicher schattiert ohne eine markantere Unterscheidung im Verhältnis von Höhe und Breite. Trotz einiger Unterschiede überwiegt auch hier die Übereinstimmung.

Die Übereinstimmung bei den Majuskeln zu verfolgen, welche nach unserer Auffassung zur halbkursiven Schrift gehören (Spalte 2 und 5), ist schwieriger, weil eine Reihe von Graphemen mehr Abstände auf der Seite von Heinrich Polan aufweist. Trotzdem finden wir aber auch hier eine Analogie des Duktus im Falle -A-, -C-, -D-, -F-, -G-, -I-, -N-, -O-, -P-, -R-, -S-, -Z-. Einige verwendete Majuskeln haben jedoch bei Polan einen einfacheren Duktus als bei Neudörffer (-N-, die Varianten -Rund -S-, -W-) Auch diese Majuskeln sind überwiegend deutlicher schattiert ohne einen markanteren Unterschied im Verhältnis von Höhe und Breite und weisen eine deutliche Übereinstimmung auf.

Die Majuskeln in den Spalten 3 und 6 gehören aufgrund ihres komplizierten Duktus und ihrer außergewöhnlichen Verzierung fraglos zur Fraktur. Diese Verzierung findet ein gemeinsames

\footnotetext{
${ }^{54}$ J. Kašpar, Úvod do novověké latinské paleografie, S. 31; J. Kašpar, Norimberská písařská škola, S. 137; I. Hlaváček, J. Kašpar, R. Nový, Vademecum, S. 84.

${ }_{55}$ W. Fugger, Ein nutzlich und wolgegrundt formular, manncherley schöner schriefften, ... 1553, Nürnberg, VKOl, (Die historischen Sammlungen) sign. 602105, p. 50 (Kanzleischrift), 52 (Kanzleischrift), 60 (Frakturschrift).

${ }^{56}$ Wie von J. Neudörffer gemeldet: ,,... ist ein rechter eingang in die fracturschrifft. Wie aigentlich aber eins aus dem andern volgt hernach ... gemein ... gewunden ... gebrochen.” BSB München, AHAD, sign. Chalc. 18 a, f. 11. Es geht um die 5. Schriftprobe in der Beilage unserer Arbeit.

${ }^{57}$ Siehe die Anmerkungen zur 1. Schriftprobe.
} 
Wesensmerkmal in einem markanten horizontalen Strich, der auf der linken Seite der Grapheme hervorragt und in eine Serie von Zierstrichen übergeht. Diese typischen Verzierungen können wir nicht nur bei allen Neudörffer'schen Graphemen dieser Art sehen, sondern auch in einer Reihe von Fällen bei Polan (-A-, -D-, -G-, -H-, -M-, -P-, -W-). Die Majuskeln der untersuchten Art haben alle eine deutliche Schattierung und dank der Verzierung meist auch ein breiteres Modul. Auch hier finden wir dank der beschriebenen Verzierung eine deutliche Übereinstimmung der Ausrichtung des Federzugs.

Auf der Basis dieser vergleichenden Modellanalyse können wir feststellen, dass zwischen der Handschrift von Heinrich Polan und der Musterschrift von Johann Neudörffer eine Reihe von gemeinsamen Merkmalen existiert, die gegenüber den Unterschieden des Duktus beider untersuchter Stadtschreiber überwiegen. Damit das Bild von Polans Rolle bei der Verbreitung neuer Formen der deutschen neugotischen Schrift in der Olmützer Stadtkanzlei vollständig ist, ist es notwendig, zu dieser positiven Feststellung gegen Ende unserer Ausführungen noch einige Bemerkungen zur Entwicklung der Handschrift Heinrich Polans hinzuzufügen.

Wenn wir die primäre älteste Schriftprobe von Polans Handschrift aus der Zeit seiner Ankunft in Olmütz ${ }^{58}$ mit seiner Schrift aus dem Jahr 1552 vergleichen ${ }^{59}$, als er Olmütz verließ, sehen wir, dass sich seine Handschrift beinahe nicht verändert hat. Unter Berücksichtigung der Tatsache, dass bereits in der ältesten Schriftprobe Polans neben der deutschen neugotischen Kursive auch zwei Zeilen der deutschen neugotischen halbkursiven Schrift belegt sind, können wir mit beträchtlicher Wahrscheinlichkeit konstatieren, dass er aus dem schlesischen Neiße nach Olmütz bereits mit einer ausgereiften, festgelegten Schrift kam, an dessen Formierung die Musterschrift der Nürnberger Schreiberschule beteiligt war. Heinrich Polan erfüllt somit auch die übrigen Kriterien, die wir uns für die Identifikation des Schreibers gesetzt haben, welcher gleichzeitig auch als Vermittler des Schrifttransfers aus anderen Gebieten auftrat.

Polans Beispiel zeigt eine mögliche Art der Übertragung der ausgereifteren neugotischen Schreibformen aus Schlesien nach Mähren und sein Fall dient gleichzeitig als Entwurf für weitere paläographische Forschungen zum Thema der Verbreitung der deutschen neugotischen Schrift zwischen diesen Gebieten, beziehungsweise zwischen ihren administrativen Zentren, im 16. Jahrhundert, welche bisher von der Forschung nicht bearbeitet worden sind. ${ }^{60}$

Wir sind uns der Tatsache bewusst, dass dieses Thema einer umfangreichen und heuristisch anspruchsvollen Forschung bedarf. Dieser Artikel soll daher nicht mehr als eine Fallstudie sein, deren Kern im Vergleich ausgewählter Schriftproben aus der besagten Hand mit der Schrift der Nürnberger Schreiberschule zum Ziel einer Feststellung ihrer Unterschiede und Übereinstimmungen besteht. Jedoch kann die Studie ein erstes Mosaiksteinchen in einer umfangreicheren Anzahl von Untersuchungen werden und einen Ausgangspunkt für weitere Forschung bilden, indem sie zunächst die Methoden und Möglichkeiten der paläographischen Analyse bei der Lösung der gegebenen Problematik überprüft hat.

\section{(Die Übersetzung des Artikels aus dem Tschechischen ins Deutsche: Robert Jodlbauer)}

\footnotetext{
58 Siehe 6. Schriftprobe.

59 Siehe 11. Schriftprobe.

${ }^{60}$ Die methodischen Verfahren der paläographischen Arbeit sind theoretisch breit ausgearbeitet (z. B.J. Kašpar, Př́spěvek k metodice výzkumu novovékého psaného písma v Čechách. Problematika evidence psaného písma. AUC-PhilosHist. 5, 1980, Z pomocných věd historických IV, S. 69-82; J. Słowiński, Rozwój, S. 12-18; K. Bobowski, Możliwości rozszerzania zakresu badań paleograficznych, in: Tradycje i perspektywy nauk pomocniczych historii w Polsce, Kraków 1995, S. 143147). Zum vorgeschlagenen Thema der Verbreitung der deutschen neugotischen Schrift zwischen Schlesien und Mittelmähren im 16. Jahrhundert haben wir aber bisher keine Fallstudie registriert. K. Bobowski beschäftigt sich mit der Problematik der Verbreitung der neugotischen Schrift aus Schlesien in die Nachbarländer vor allem aus dem schlesischen Betrachtungswinkel (K. Bobowski, Ewolucja, S. 18, 30-33).
} 


\section{Quellenedition mit Schriftproben der im Vergleichsmaterial verwendeten neugotischen Schrift}

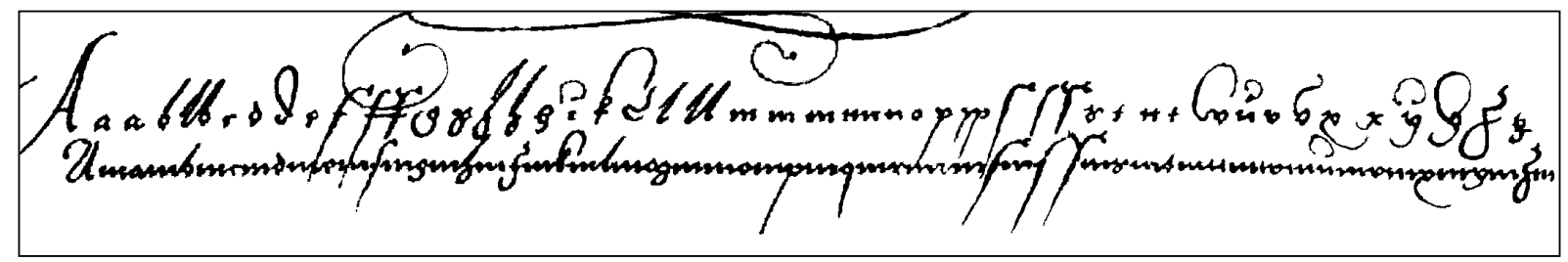

\section{Schriftprobe}

Johann Neudörffer der Ältere, die deutsche neugotische Kursiv (alphabetische Reihen, überwiegend Minuskeln), 1538, Nürnberg

Ein gute ordnung ..., Bayersiche Staatsbibliothek [weiter: BSB] München, Abteilung für Handschriften und Alte Drucke [weiter: AHAD], sign. Chalc. 18 a, f. 40

\section{Transliteration:}

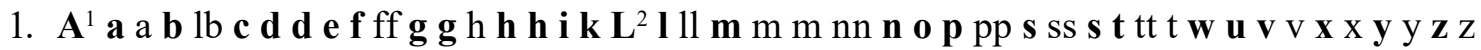

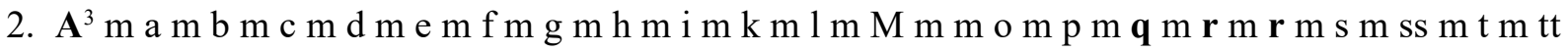
$\mathrm{m}$ w $\mathrm{m} u \mathrm{~m} v \mathrm{~m} \mathrm{x} \mathrm{m}$ y $\mathrm{m} \mathbf{z} \mathrm{m}$

\section{Anmerkungen zur Edition:}

1) Die Majuskel -A-, die am Anfang der alphabetischen Reihe der Minuskeln steht, wie bei Neudörffer üblich, wurde in der zusammenfassenden Tabelle II verwendet.

2) Die Majuskel -L- wurde nicht systemkonform in die Reihe der Minuskeln in die Tabelle II eingereiht.

3) Das Graphem -A-, welches in einer ähnlichen Position ist wie -A- in der vorhergehenden Zeile, stellt eine Majuskel mit deutlich kursiver Ausrichtung des Federzugs dar, welche durch die Vergrößerung der einfachen Minuskel -a- entstanden ist. Die angeführte Majuskel nimmt das typische Merkmal des Graphems -A- und des -a- der neugotischen Kursive vorweg, zu welchem der offene Ballen wird. 


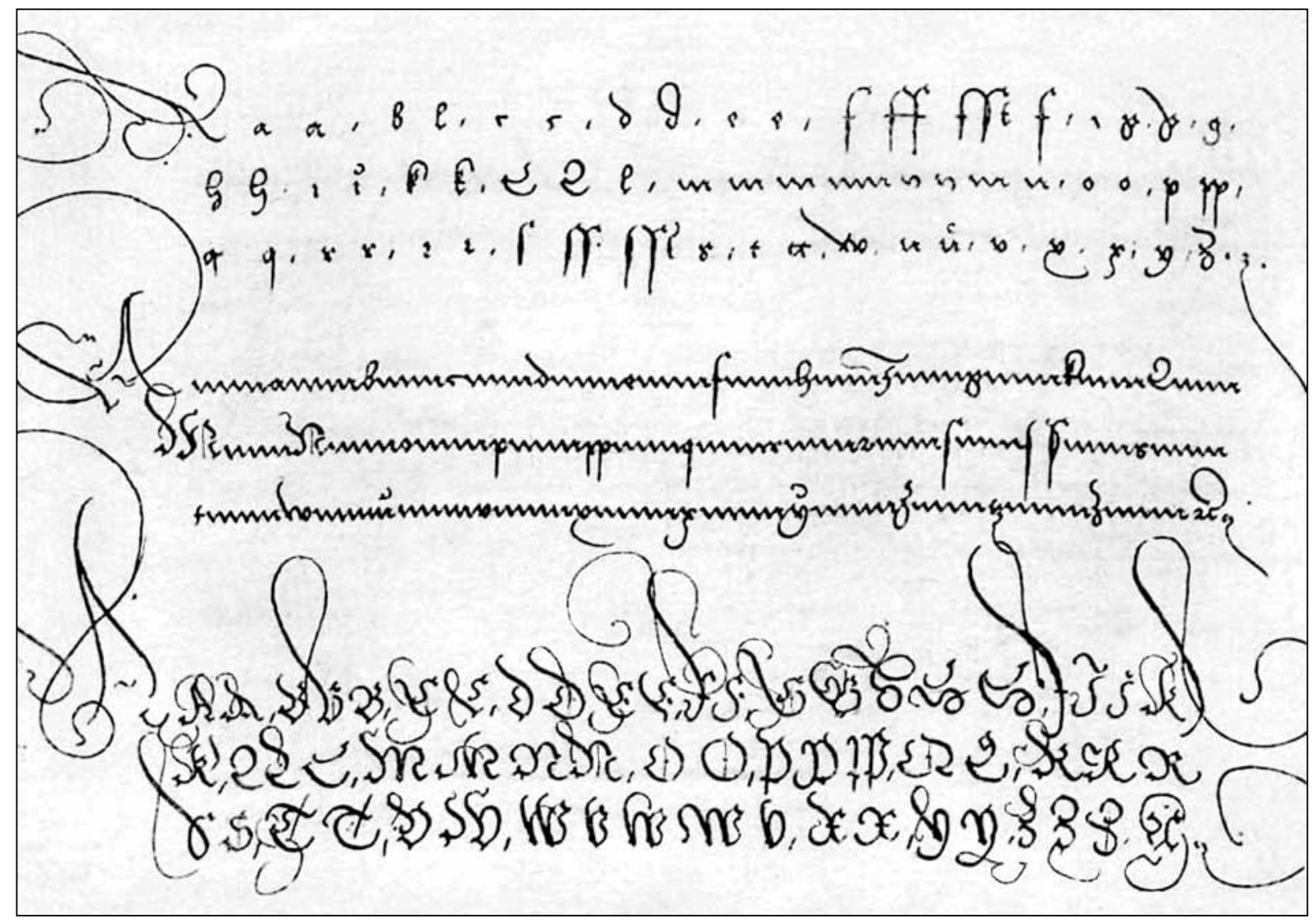

\section{Schriftprobe}

Johann Neudörffer der Ältere, die deutsche neugotische Schrift mit den halbkursiven Elementen (alphabetische Reihen, Majuskeln auch Minuskeln), 1538, Nürnberg

Ein gute ordnung ..., BSB München, AHAD, sign. Chalc. 18 a, f. 27

\section{Transliteration:}

1. A a $\mathbf{a}, \mathbf{b} 1, \mathbf{c} \mathrm{c}, \mathrm{d} \mathbf{d}, \mathbf{e}$ e, $\mathbf{f}$ ff fft $\mathrm{f},{ }^{+1} \mathbf{g} \mathrm{g}, \mathbf{g}$,

2. h h, i i, k k, L L l, m m m nn n n m n, o o, p pp,

3. q q, r r, r r, s ss sst $\mathbf{s}, \mathbf{t}$ tt, w, u $\mathbf{u}, \mathrm{v}, \mathbf{x}, \mathbf{x}, \mathrm{y}, \mathrm{z}, \mathrm{z}$.

4. A $\mathrm{mm}$ a $\mathrm{mm} \mathrm{b} \mathrm{mm} \mathrm{c} \mathrm{mm} \mathrm{d} \mathrm{mm}$ e $\mathrm{mm} \mathrm{f} \mathrm{mm} \mathrm{h} \mathrm{mm} \mathrm{I} \mathrm{mm} \mathrm{g} \mathrm{mm} \mathrm{k} \mathrm{mm} \mathrm{L} \mathrm{mm}$

5. $\mathrm{M} \mathrm{mm} \mathrm{N} \mathrm{mm} \mathrm{o} \mathrm{mm} \mathrm{p} \mathrm{mm} \mathrm{pp} \mathrm{mm} \mathrm{q} \mathrm{mm} \mathrm{r} \mathrm{mm} \mathrm{r} \mathrm{mm} \mathrm{s} \mathrm{mm} \mathrm{ss} \mathrm{mm} \mathrm{s} \mathrm{mm}$

6. $\mathrm{t} \mathrm{mm} \mathrm{w} \mathrm{mm} \mathrm{u} \mathrm{mm} v \mathrm{~mm} \times \mathrm{mm} \times \mathrm{mm}$ y $\mathrm{mm} \mathbf{z} \mathrm{mm}$ tz nnm $\mathrm{z} n n m$ etc $\mathrm{z}$.

7. A A A, B B B, C C, D D, E E, F F, G G H H, I I I K

8. K, L L L, M M N N, O O, P P PP, Q Q, R R R

9. S S, T T, V W W V W W V, X X, Y Y, Z Z Z, Etc.

\section{Anmerkungen zur Edition:}

1) Mit dem Zeichen ,+, bezeichnen wird die Teile der Buchstaben, soweit sie eigenständig als Teilphase eines Duktus dieser Buchstaben vor der Abbildung ihrer kompletten Grapheme dargestellt sind. 


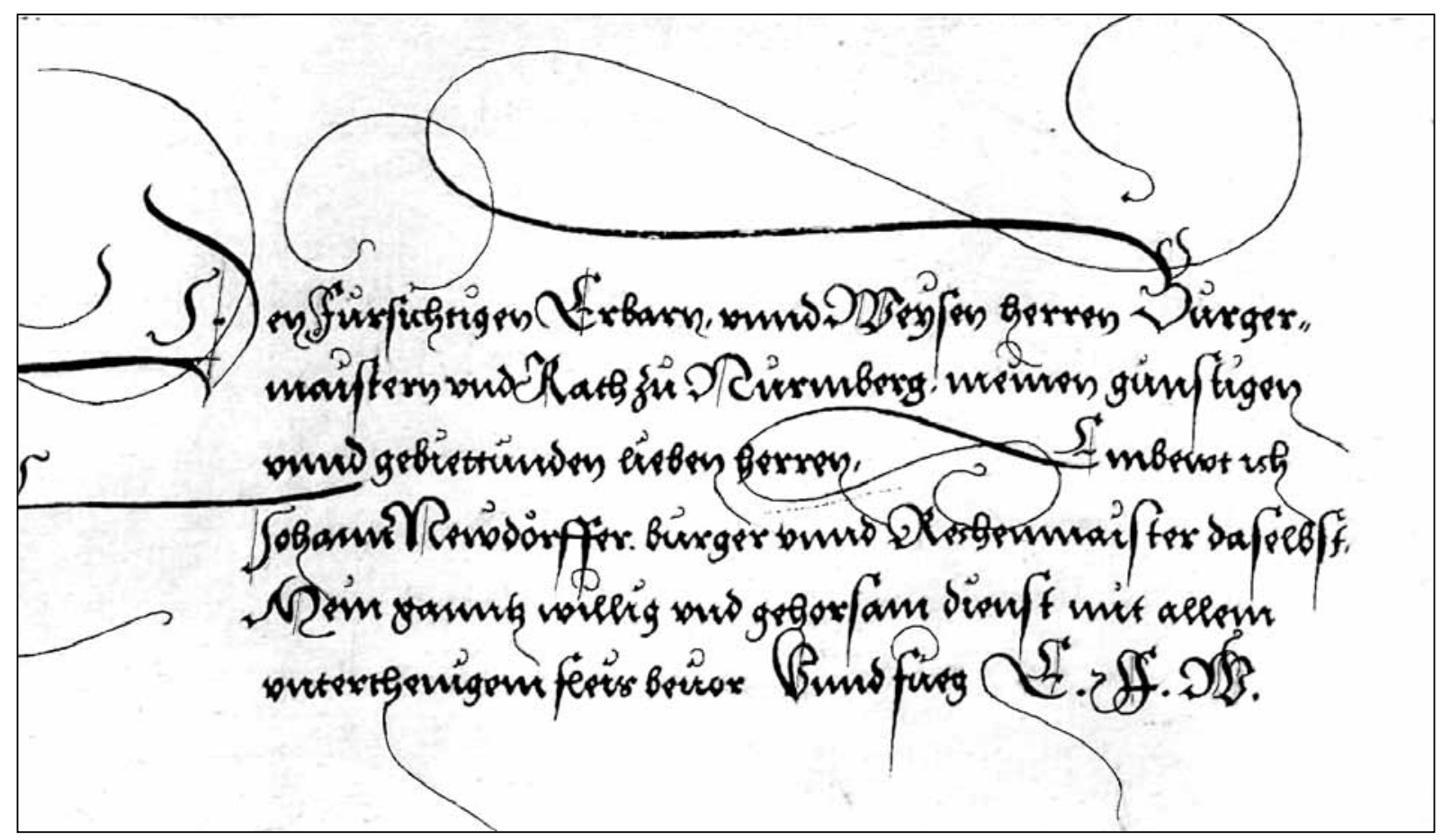

\section{Schriftprobe}

Johann Neudörffer der Ältere, die deutsche neugotische Halbkursivschrift (Fließtext), 1538, Nürnberg Ein gute ordnung ..., BSB München, AHAD, sign. Chalc. 18 a, f. 34

\section{Transliteration:}

1. Den Fursichtigen Erbarn vnnd Weysen herren Burger-

2. maistern vnd Rath zu Nurmberg, meinen gunstigen

3. vnnd gebiettunden lieben herren. Embewt ich

4. Johann Newdorffer, burger vnnd Rechenmaister daselbst

5. Mein ganntz willig vnd gehorsam dienst mit allem

6. vnterthenigem fleis beuor Vnnd fueg E. FF. W. 


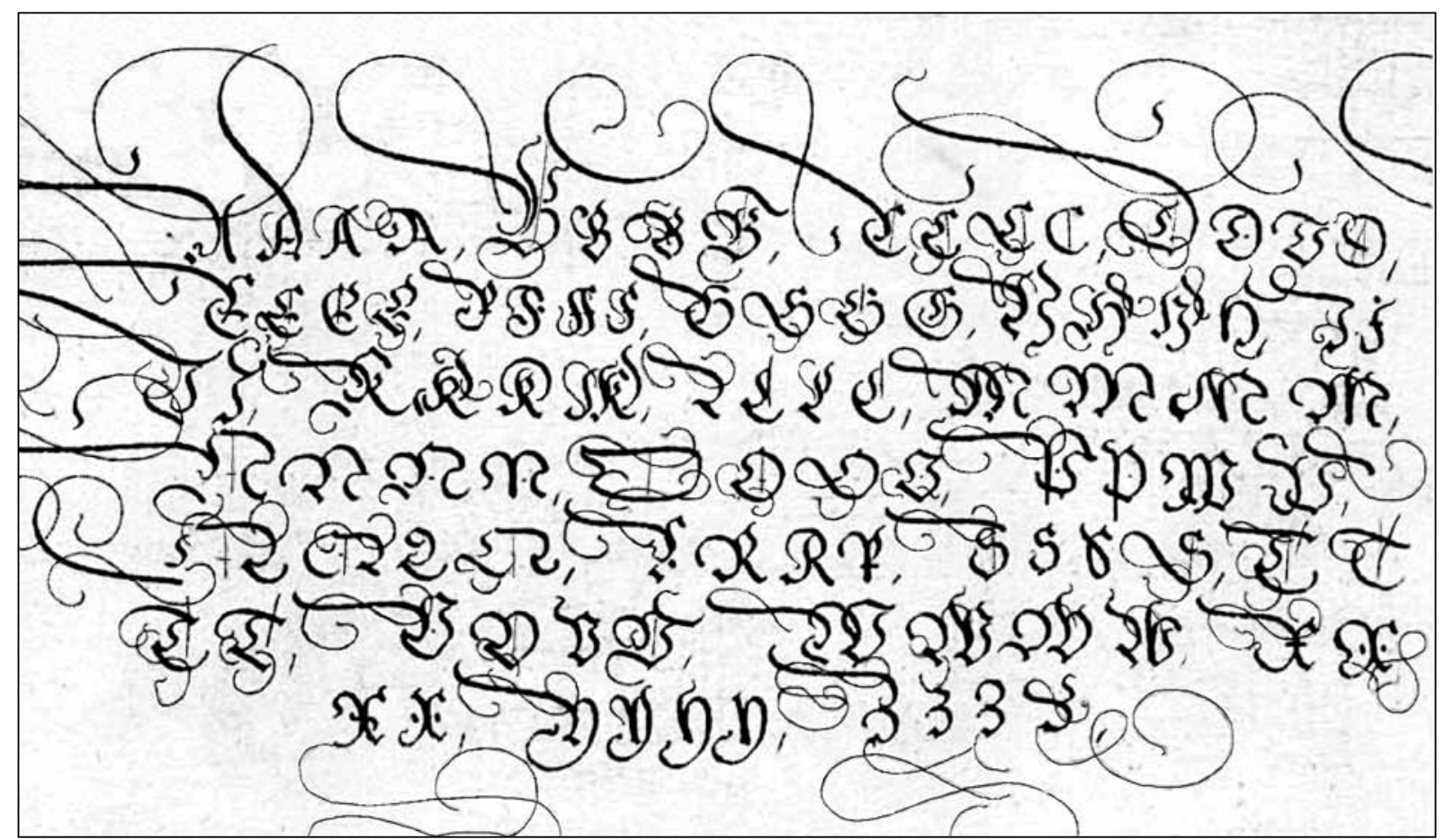

\section{Schriftprobe}

Johann Neudörffer der Ältere, verschiedene Formen der deutschen neugotischen Schrift (alphabetische Reihe der Majuskeln), 1538, Nürnberg

Ein gute ordnung ..., BSB München, AHAD, sign. Chalc. 18 a, f. 10

\section{Transliteration:}

1. A A A A B B B B C C C C D D D D

2. E E E E F F F F G G G G H H H H I I

3. I I K K K K L L L L M M M M

4. N N N N O O O O P P PP P

5. Q Q Q Q R ${ }^{1} \mathbf{R} \mathbf{R} \mathbf{R}$ S S S S T T

6. T T V V V V W W W W X X

7. X X Y Y Y Y Z Z Z Z

\section{Anmerkungen zur Edition:}

1) Am Beispiel der Majuskel -R- ist die Variabiliät der Ausrichtung des Federzugs zu sehen. Während das bezeichnete Graphem als das am meisten verzierte fraglos zu den Majuskeln der deutschen neugotischen gezeichneten Schrift (Fraktur) gehört, bewerten wir die übrigen Exemplare derselben Handschrift aufgrund ihrer einfacheren Kaligraphie nicht so eindeutig. Im Rahmen des zusammenhängenden Textes können sie auch zwischen den Graphemen mit einem eher halbkursiven und kursivem Duktus die Rolle der Majuskeln spielen. 


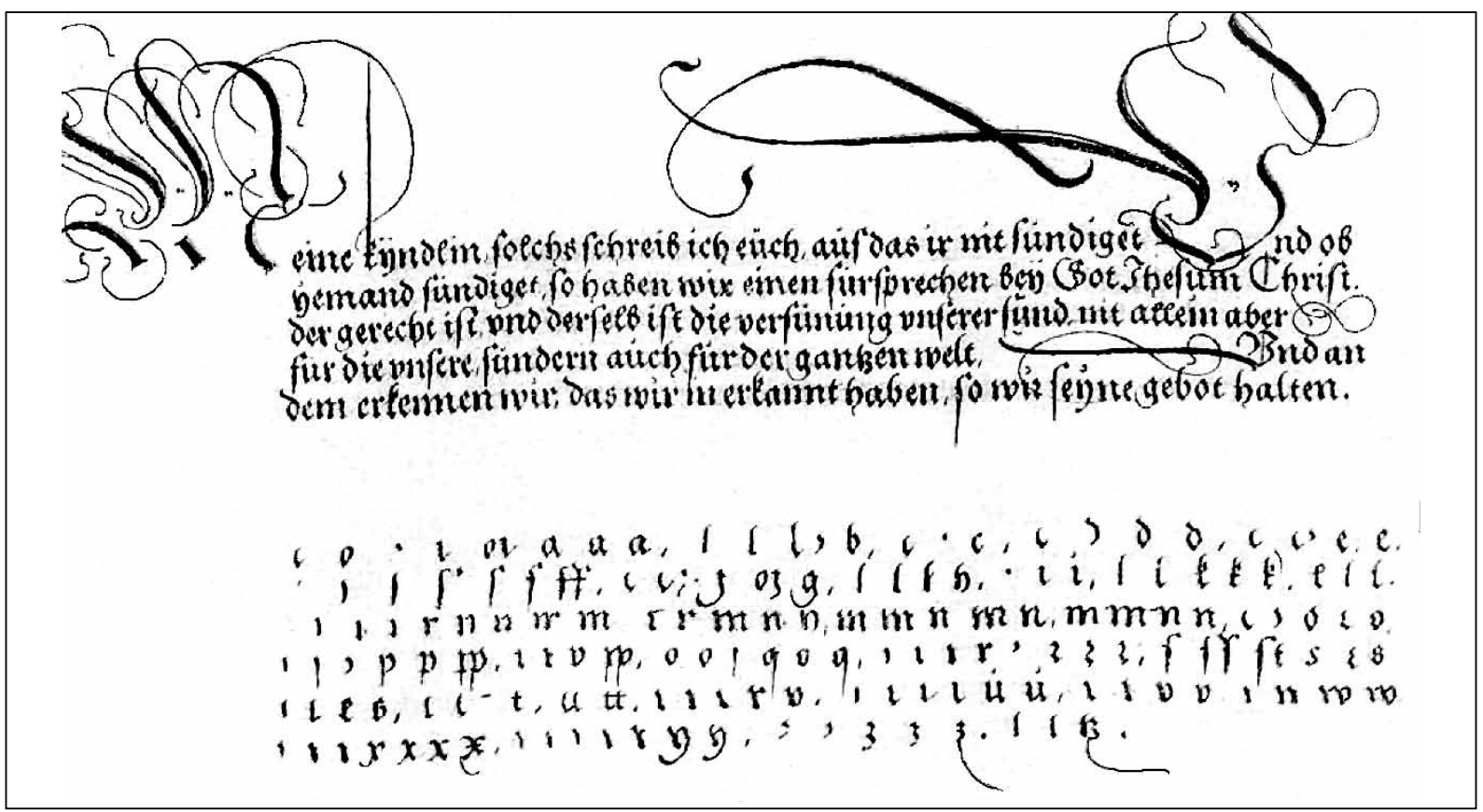

\section{Schriftprobe}

Johann Neudörffer der Ältere, die deutsche neugotische gezeichnete Schrift - Fraktur (Fließtext, alphabetische Reihe der Minuskeln), 1538, Nürnberg

Ein gute ordnung ..., BSB München, AHAD, sign. Chalc. 18 a, f. 52

\section{Transliteration:}

1. Meine kyndlin, solchs schreib ich euch auf das ir nit sundiget. Vnd ob

2. yemand sundiget, so haben wir einen fursprechen bey Gott Ihesum Christ,

3. der gerecht ist vnd derselb ist die versünnung vnserer sund nit allein, aber

4. fur die vnsere sündern auch für der gantzen welt. Vnd an

5. dem erkennen wir, das wir in erkannt haben, so wir seyne gebot halten.

6. $+^{1}++++\mathbf{a} \mathbf{a}^{2} \mathbf{a},++++\mathbf{b},++\mathbf{c},++\mathrm{d} \mathbf{d},++\mathbf{e}$ e,

7. $++++++\mathbf{f ~ f f},++,++\mathbf{g},+++\mathbf{h},++\mathbf{i},++\mathrm{k} \mathrm{k} \mathrm{k}, \mathbf{l} 11$,

8. $+++++++\mathbf{m},++\mathbf{m}^{3} \mathrm{n} \mathrm{n}, \mathrm{m} \mathrm{m} \mathrm{n} \mathrm{m} \mathrm{n,} \mathrm{m} \mathrm{m} \mathrm{n} \mathrm{n},++\mathbf{o}+\mathbf{o}$,

9. $+++\mathrm{p} \mathrm{p} \mathrm{pp},++\mathrm{v}, \mathrm{w},+++\mathbf{q}+\mathrm{q},+++\mathbf{r},+\mathrm{rr} \mathbf{r}, \mathbf{s}$ ss st $++\mathbf{s}$

10. $+++\mathrm{s},+++\mathbf{t},++\mathrm{tt},++++\mathbf{v},++++\mathbf{u}, \mathrm{u},++++++\mathrm{w} \mathbf{w}$

11. $++++\mathbf{x} \times \mathbf{x},+++++\mathrm{y} \mathbf{y},++\mathbf{z} \mathbf{z} \mathbf{z},++\mathrm{tz}$.

\section{Anmerkungen zur Edition:}

1) Wie bereits angeführt, bezeichnen wir mit dem Zeichen „,+" die Teile der Buchstaben, soweit sie als Teilphase des Duktus dieser Buchstaben vor der Abbildung ihrer kompletten Grapheme selbstständig abgebildet sind.

2) Variante der Minuskel -a- mit zweimal gebrochenem Bogenstrich, der den Ballen des Buchstabens mitverfasst.

3) Variante der Minuskel -m- mit zwiefach gebrochenen Schäften. 


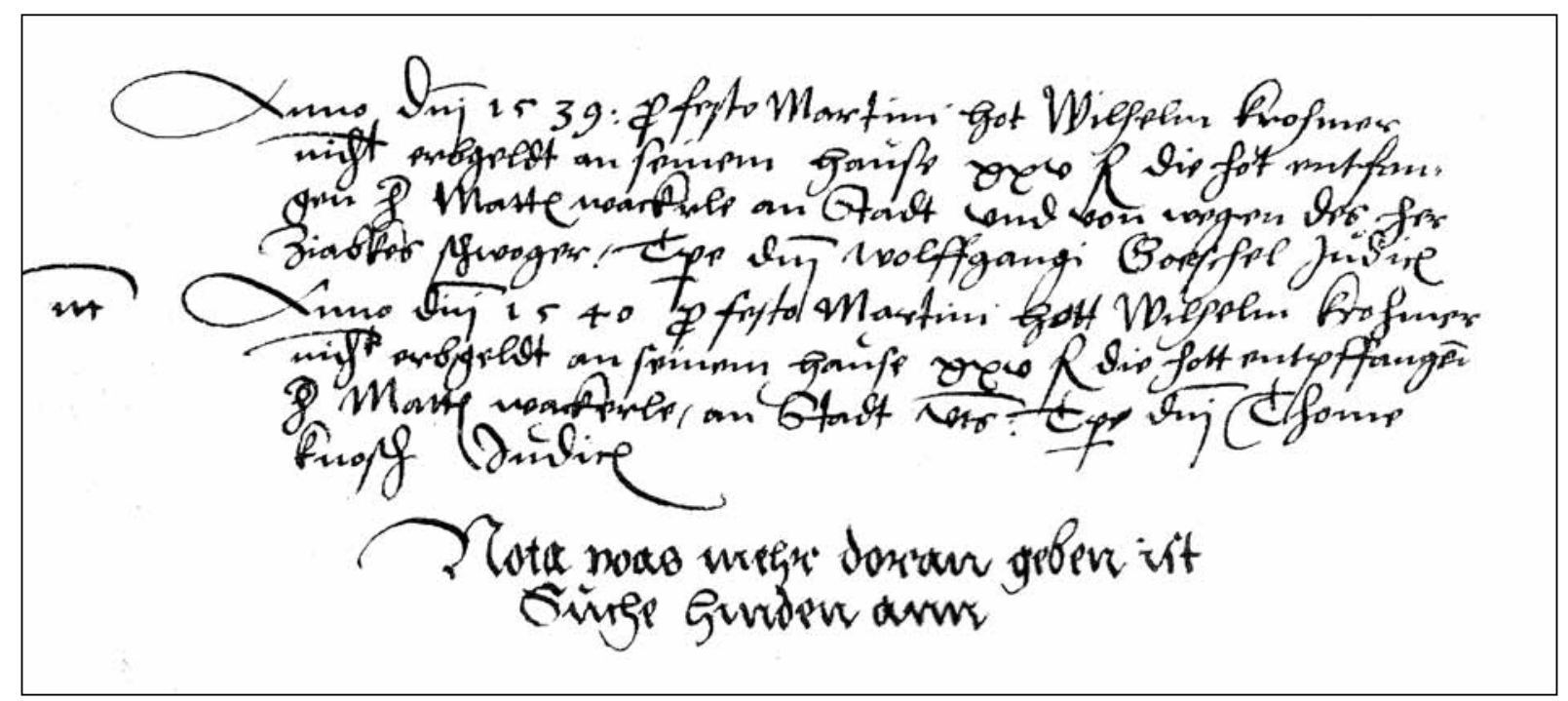

\section{Schriftprobe}

Heinrich Polan, die deutsche neugotische Kursiv ${ }^{1}$, die deutsche neugotische Halbkursivschrift ${ }^{2}$ (Fließtext), [1539, November 10.], 1540, November 10., Olomouc

Die Einschreibungen der Rückzahlungen auf das Haus, das Gerichtsprotokoll ..., Státní okresní archiv (Das Staatsbezirksarchiv) [weiter: SOkA] Olomouc, fond „Archiv města Olomouc” (der Archivbestand „Archiv der Stadt Olmütz”) [weiter: AMO], Bücher, sign. 1033, inv. č. 1658, f. 71v

\section{Transliteration:}

1. Anno d[omi]ni 1539: p[ro] festo Martini hot Wilhelm krohmer ${ }^{1}$

2. nid[ergeleg]t erbgeldt an seinem hause xxv f[lorene], die hot enthan-

3. gen h[err] Matt[es] wackerle an Stadt vnd von wegen des her

4. Ziabkes schwoger. T[em]p[or]e d[omi]ni wolfgangi Goeschel Iudic[is].

5. Ite[m] Anno d[omi]ni $1540 \mathrm{p}[\mathrm{ro}]$ festo Martini hott Wilhelm krohmer

6. nid[ergeleg]t erbgeldt an seinem hause xxv f[lorene], die hot entpffange[n]

7. h[err] Matt[es] wackerle, an Stadt vts[upra]. T[em]p[or]e d[omi]ni Thome

8. knosch Iudic[is].

9. Nota, was mehr doran geben ist, ${ }^{2}$

10. Suche hinden ann.

\section{Anmerkungen zur Edition:}

1) Als deutsche neugotische Kursive klassifizieren wir die Handschrift in den Zeilen 1.-8.

2) Die neugotische halbkursive Schrift ist in den Zeilen 9.-10. belegt. 


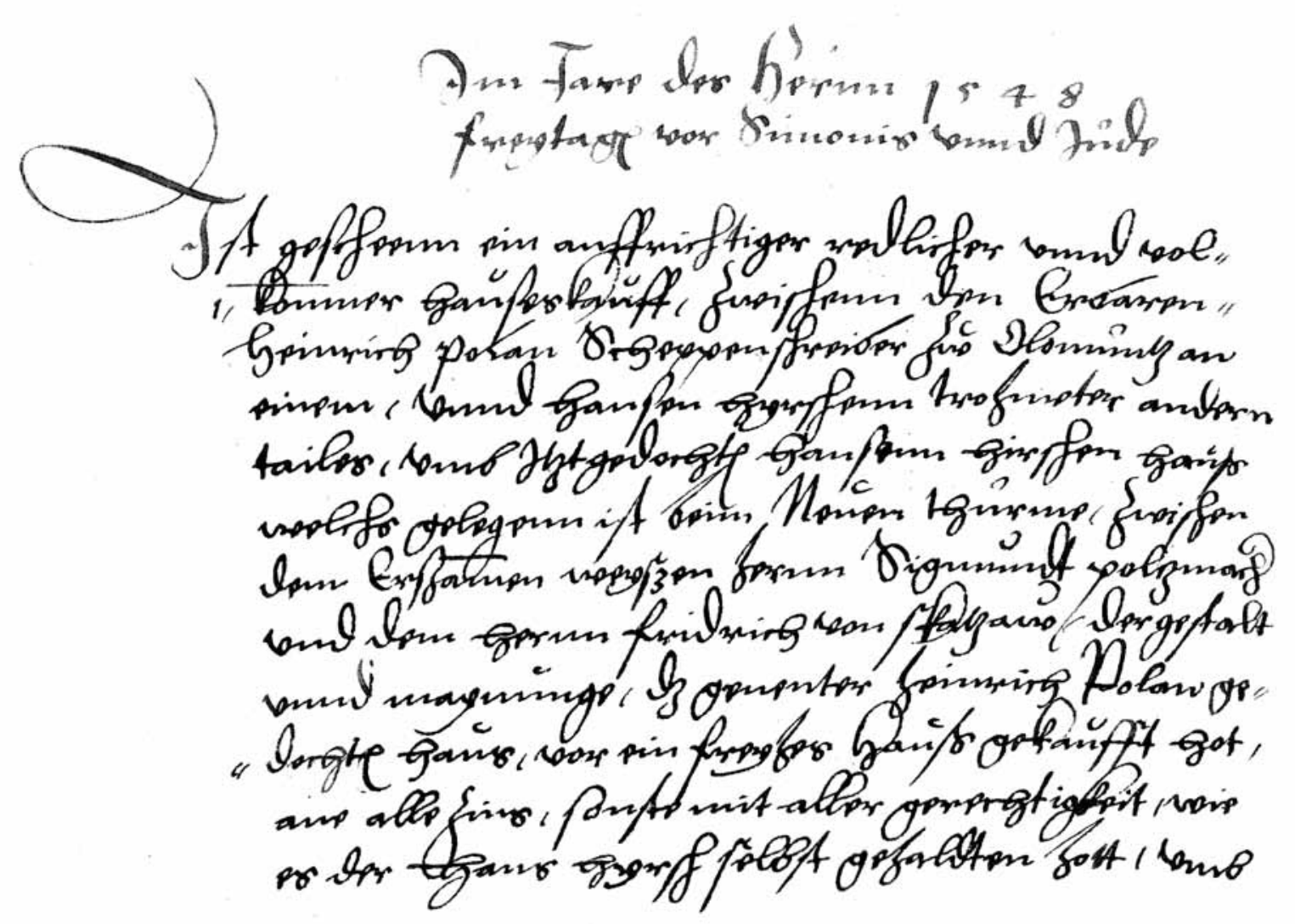

\section{Schriftprobe}

Heinrich Polan, die deutsche neugotische Kursiv (Fließtext), 1548, Oktober 26., Olomouc Die Einschreibung des Kaufes eines Hauses, das Gerichtsprotokoll ..., SOkA Olomouc, AMO, Bücher, sign. 1046, inv. č. 1671, f. $49 \mathrm{v}$

\section{Transliteration:}

1. Im Iare des Hernn 1548

2. freytag[es] vor Simonis vnnd Iude.

3. Ist gescheenn ein auffrichtiger redlicher vnnd vol-

4. kom[m]ner hauseskauff zwischen den Erbaren

5. Heinrich Polan Scheppenschreiber zw Olomuntz

6. einem, vnnd hansen hyrschenn trohmeter andern

7. tailes, vmb Itztgedocht[en] hansenn hirschen hauß

8. welchs gelegenn ist biem Neuen thurme, zwischen

9. dem Erßam[m]en weyszen hernn Sigmundt polczmach[er]

10. vnd dem hernn fridrich von skatzaw, dergestalt

11. vnnd maynunge, $d[a ß]$ genenter heinrich Polan ge-

12. docht[es] haus vor ein freyhes hauß gekaufft hot,

13. ane alle zins, sonste mit aller gerechtigkeit wie

14. es der Hans hyrsch selbst gehaldten hott vmb 


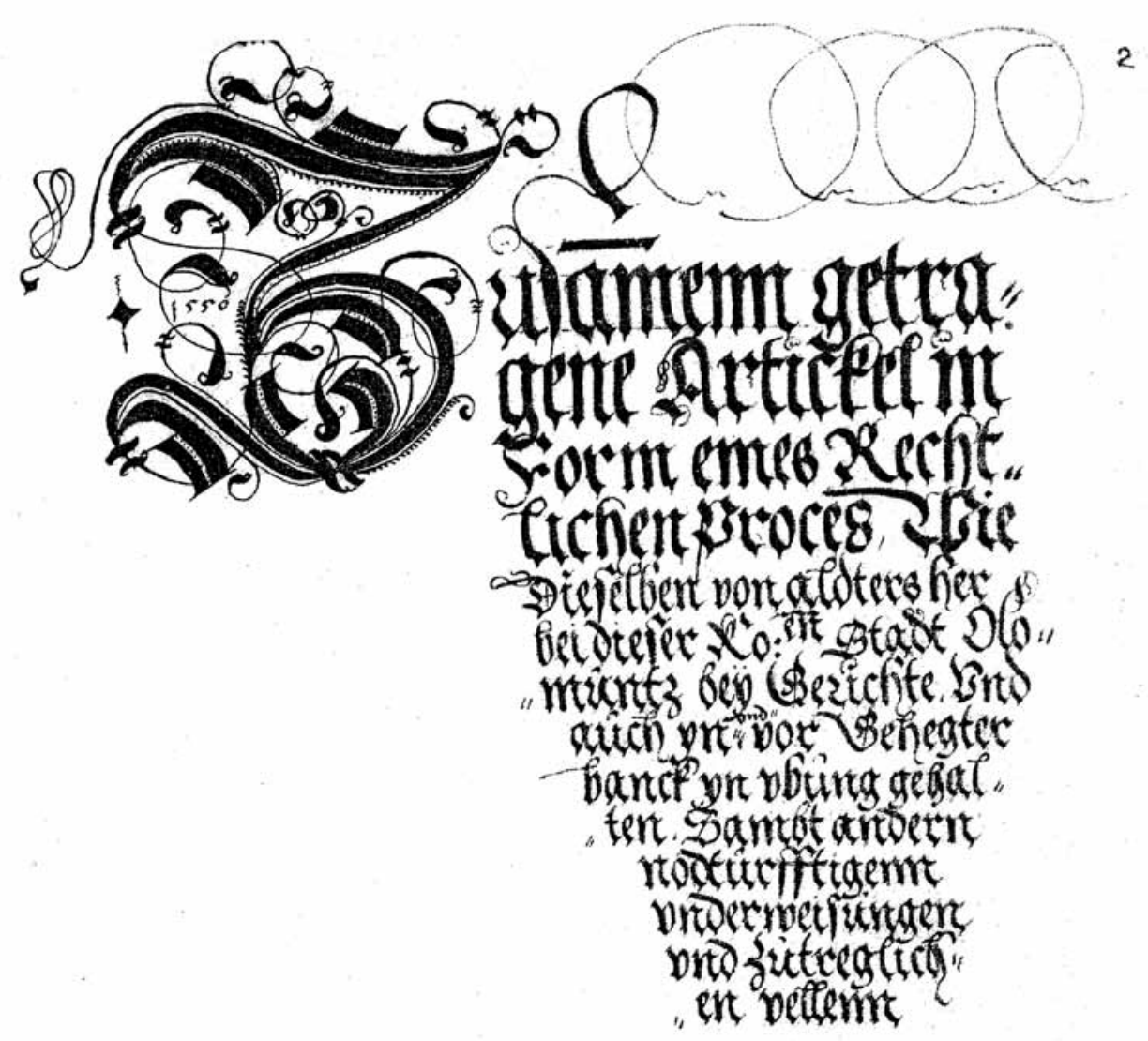

\section{Schriftprobe}

Heinrich Polan, die deutsche neugotische gezeichnete Schrift-Fraktur (Fließtext), 1550, Olomouc Die Titelseite, Die Rechtsartikel ..., SOkA Olomouc, AMO, Bücher, sign. 116, inv. č. 90, f. 2r

\section{Transliteration:}

1. Zusam[m]enn getra-

2. gene Artickel in

3. Form eines Recht-

4. lichen Proces Wie

5. Dieselben von aldters her

6. bei diser Ko[niglichen] Stadt Olo-

7. muntz bey Gerichte Vnd

8. auch yn vor Gehegter

9. banck yn vbung gehal-

10. ten. Sambt andern

11. nodturfftigenn

12. vnderweisungen

13. vnd zutreglich-

14. en vellenn 


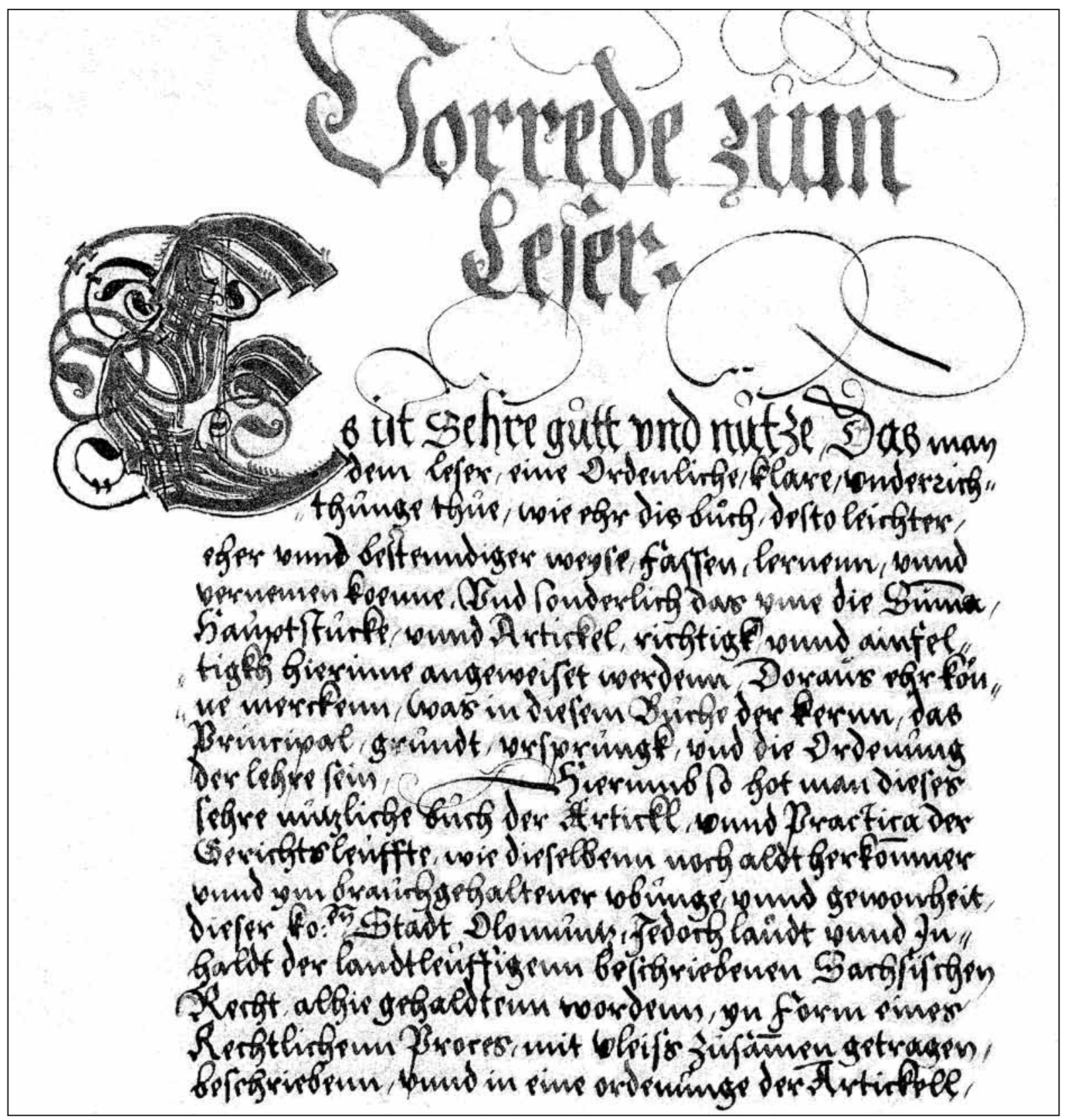

\section{Schriftprobe}

Heinrich Polan, die deutsche neugotische gezeichnete Schrift-Fraktur ${ }^{1}$, die deutsche neogotische

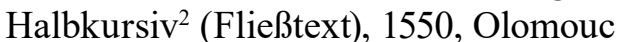
das Vorwort, Die Rechtsartikel ..., SOkA Olomouc, AMO, Bücher, sign. 116, inv. č. 90, f. 3r

Transliteration:

1. Vorrede zum

2. Leser.

3. Es ist Sehre gutt vnd nutze, Das man

4. dem leser eine Ordenliche, klare, vnderrich- 
5. thunge thue, wie ehr dis buch, desto leichter,

6. eher vnnd bestenndiger weyse, fassen, lernenn vnnd

7. vernemen koenne. Vnd sonderlich das yme die Sum[m]a,

8. Hauptstucke vnnd Artickel, richtig vnnd ainfel-

9. tigkh hierinne angeweiset werdenn, Doraus ehr kön-

10. ne merckenn, was in diesem Buche der kernn, das

11. Principal, grundt, vrsprungk, vnd die Ordenung

12. der lehre sein. $\mathbf{H}^{3}$ ierumb so hot man dieses

13. sehre nützliche buch der Artickl vnnd Practica der

14. Gerichtsleuffte, wie dieselbenn noch aldt herkom $[\mathrm{m}]$ ner

15. vnnd ym brauchgehaltener vbunge vnnd gewonheit

16. dieser ko[niglichen] Stadt Olomuntz, Iedoch laudt vnnd In-

17. haldt der landtleuffigenn beschriebenen Sachsischen

18. Recht, alhie gehaldtenn wordenn, yn Form eines

19. Rechtlichenn Proces, mit vleiss $\mathbf{Z}^{4}$ usam[m]en getragen,

20. beschriebenn, vnnd in eine ordenunge der Artickell,

\section{Anmerkungen zur Edition:}

1) Als Fraktur klassifizieren wir die Handschrift in der 1. und 2. Zeile und im größten Teil der 3. Zeile.

2) Die neugotische halbkursive Schrift ist in den Zeilen 4. - 20. belegt.

3) Die Majuskel -H- wurde aufgrund ihrer Gestaltung als Graphem klassifiziert, welches eher zur Sammlung der Frakturschriften gehört, obwohl sie sich im Text mit halbkursivem Duktus befindet.

4) Obwohl die Definition der Majuskel -Z- in einer Reihe von Fällen nicht eindeutig ist, weil der Schaft dieses Graphems häufig in den oberen Bereich mit einem deutlichen Bogen gedehnt wird, bewerten wir dieses Exemplar v. a. aufgrund ihrer Massigkeit, die durch die größere Breite ihres Moduls gegeben ist, als Majuskel. 


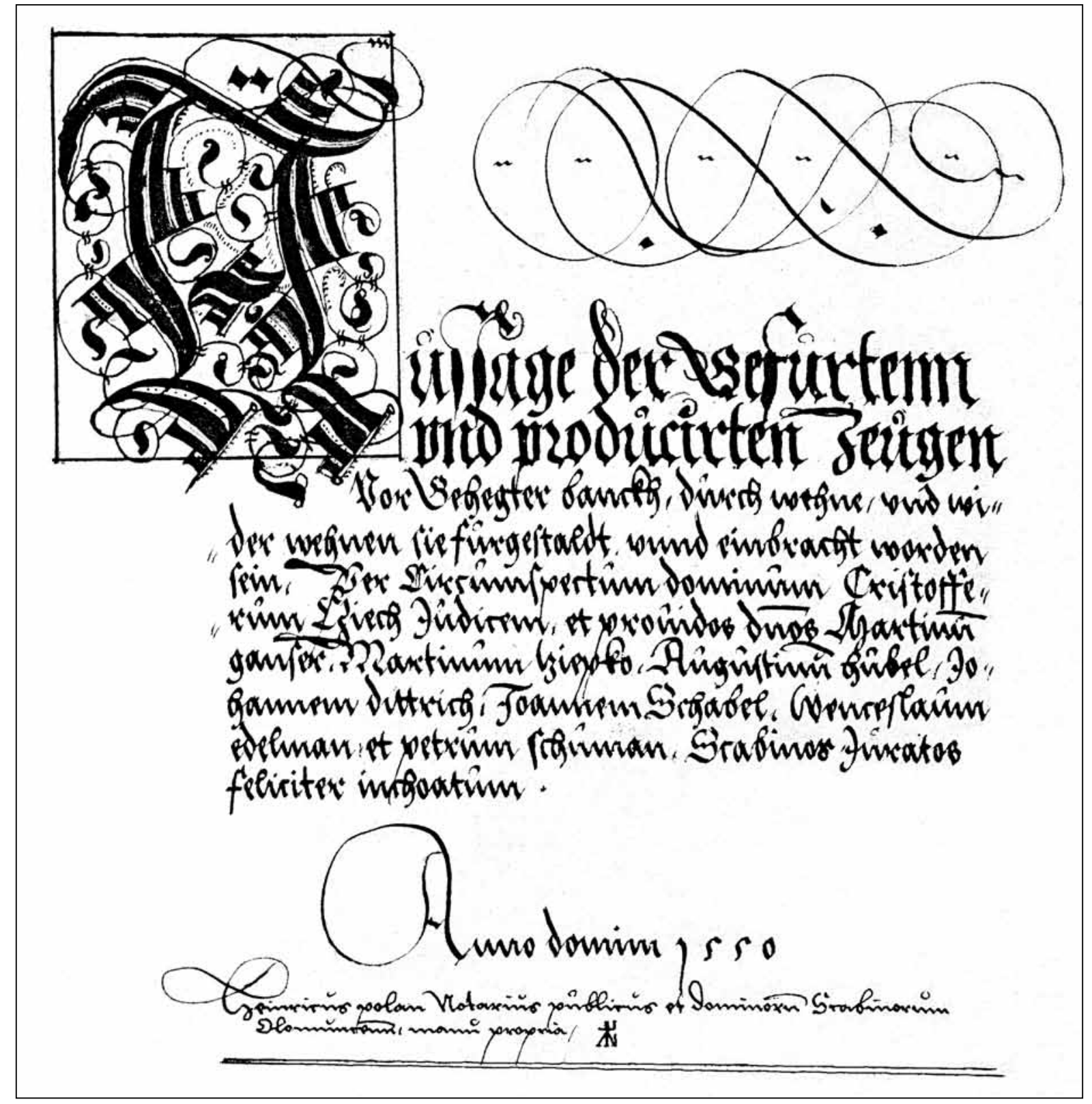

10. Schriftprobe

Heinrich Polan, die deutsche neugotische gezeichnete Schrift-Fraktur ${ }^{1}$, die deutsche neugotische Halbkursiv ${ }^{2}$, die deutsche neugotische Kursiv (Fließtext), 1550, Olomouc

Die Anfangs Einschreibung, Das Zeugnisbuch ..., SOkA Olomouc, AMO, Bücher, sign. 189, inv. č. 2046, f. $1 \mathrm{r}$

Transliteration:

1. Aussage Der Gefurtenn

2. vnd producirten Zeugen

3. Vor Gehegter banckh, durch wehne, vnd wi-

4. der wehnen sie furgestaldt vnnd einbracht worden 
5. sein. Per Circumspectum dominum Cristoffe-

6. rum Cziech Iudicem, et providos d[omi]nos $\mathbf{M}^{4}$ artinu[m]

7. ganser, $\mathbf{M}^{5}$ artinum Cziepko, Augustinum hubel, Io-

8. hannem Dittrich, Ioannem Schabel, Wenceslaum

9. edelman et petrum schuman, Scabinos Iuratos

10. feliciter inchoatum.

11. Anno domini 1550.

12. Heinricus polan Notarius publicus et Dominoru[m] Scabinorum

13. Olomunce[nsiu]m, manu propria $\mathrm{X}^{6}$

\section{Anmerkungen zur Edition:}

1) Als Fraktur klassifizieren wir die Schrift in den Zeilen 1. - 2.

2) Die neugotische halbkursive Schrift ist in den Zeilen 3. - 11. belegt.

3) Als deutsche neugotische Kursive klassifizieren wir die Schrift in den Zeilen 12. - 13.

4) Die Majuskel -M- wurde aufgrund ihres Aussehens als Graphem klassifiziert, welches eher der Frakturschriften zuzuordnen ist, obwohl sie sich in einem Text mit halbkursivem Duktus befindet. Bei einer Undeutlichkeit der Halbkursiven in der untersuchten Zeit handelt es sich jedoch um nichts Ungewöhnliches.

5) Die Variante der Majuskel -M-, die auf ältere Weise als Zusammensetzung des Majuskel -Aund des zweiten anschließenden Schaftes gebildet ist, der im unteren Bereich in eine Schleife übergeht, haben wir mit Blick auf die doppelte Durchbrechung der Ballens ebenfalls als Variante der Grapheme der Faktur eingereiht.

6) Das Zeichen „X” steht für das Notarszeichen von Heinrich Polan. V. Spáčil: Písaři a kanceláře města Olomouce do roku 1786, Olomouc 2001, s. 306, pozn. 21. 


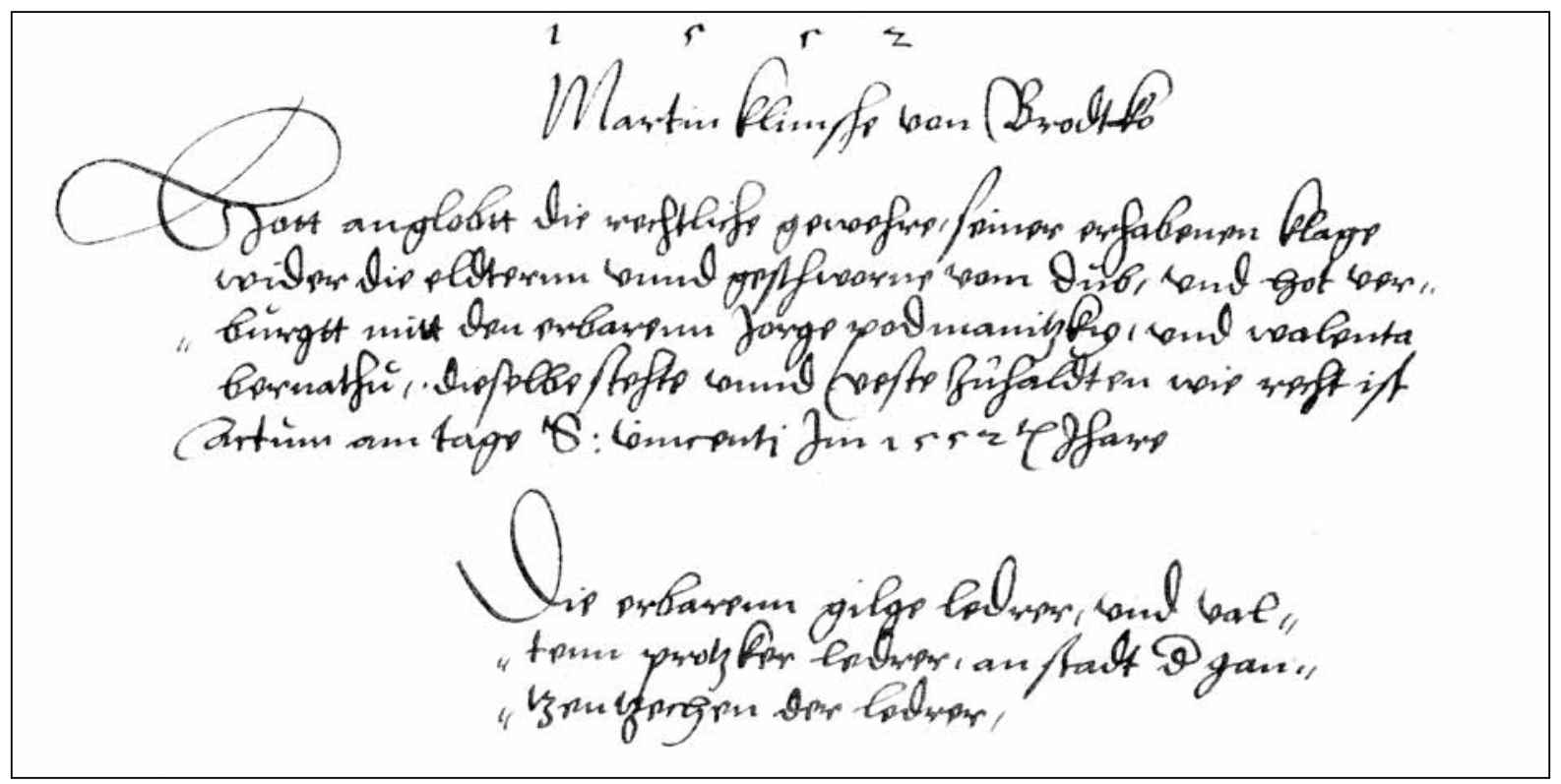

\section{Schriftprobe}

Heinrich Polan, die deutsche neugotische Kursiv (Fließtext), 1552, Januar 22., Olomouc

Der Streit von Martin Klimsche, Das Buch der Urteile ..., SOkA Olomouc, AMO, Bücher, sign. 198, inv. č. 2037, f. 262 r

\section{Transliteration:}

1. 1552

2. Martin Klimsche von Brodtko

3. $\mathrm{H}^{1}$ ott anglobtt die rechtliche gewehre, seiner erhabenen klage

4. wider die eldternn vnnd geschworne vom Dub, vnd hot ver-

5. burgtt mitt den erbarenn Iorge podmanitzky, vnd walenta

6. bernathu, dieselbe stehte vnnd veste zuhaldten wie recht ist.

7. Actum am tage S[ancti] vincenti Im 1552 Ihare.

8. Die $^{2}$ erbarenn gilge ledrer, vnd val-

9. tenn protzker ledrer, an stadt d[er] gan-

10. tzen tzechen der ledrer,

\section{Anmerkungen zur Edition:}

1) Beachtung verdient Polans typische Majuskel -H-, welche mit einer markanten oberen Schleife geschmückt ist, welche durch eine weitere Schleife nach links in die Gestalt einer liegenden kursiven acht übergeht. Diese Majuskel können wir bereits in der 10. Schriftprobe in der 12. Reihe verfolgen.

2) In der 8. - 10. Reihe folgt die Überschrift des folgenden Eintrags. 


\section{Zusammengefaßte Vergleichstabellen}

\begin{tabular}{|c|c|c|c|c|c|c|}
\hline \multicolumn{7}{|c|}{ I. } \\
\hline & 1 & 2 & 3 & 4 & 5 & 6 \\
\hline a & 4, & d & $a a$ & $a \mathfrak{a}$ & a & $\mathfrak{a} \mathbb{a}$ \\
\hline b & b6 & B & 6 & bo & 8 & 6 \\
\hline c & $r$ & 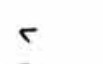 & c & $r r$ & $\hat{\imath}$ & c \\
\hline d & $\theta_{s}$ & $\theta$ & $\mathfrak{b}$ & $\vartheta d$ & $\delta$ & $\partial$ \\
\hline e & $P$ & 8 & $e$ & $p$ & e & p \\
\hline f & $f$ & $f$ & $f$ & $f$ & $f$ & $f$ \\
\hline g & 98 & 98 & $\mathfrak{G}$ & $\theta g$ & 9 & 9 \\
\hline h & $g\}$ & $\xi \rho$ & $\mathfrak{h}$ & $87 f$ & g & $h \mathrm{~s}$ \\
\hline i & $P_{i}$ & i & $i$ & $i$ & i & $i$ \\
\hline $\mathbf{k}$ & $f$ & f & $\xi^{\prime}$ & f), & $p$ & p \\
\hline 1 & 1 & $\ell$ & e & let & \& & $\varphi$ \\
\hline m & $m$ & $m$ & $m m$ & $m$ & $m$ & $m$ \\
\hline $\mathbf{n}$ & $n$ & $n$ & $\mathfrak{n} \mathfrak{n}$ & $w$ & $n$ & $n$ \\
\hline o & - & $\circ$ & 00 & 0 & 0 & 0 \\
\hline p & $p$ & $p$ & P & $\varnothing$ & $\varphi$ & - \\
\hline$q$ & 9 & 9 & 9 & - & - & - \\
\hline $\mathbf{r}$ & $x$ & $x$ & $r$ & rr & $x$ & $r$ \\
\hline $\mathrm{r}$ & ${ }^{2} \mathrm{C}$ & 2 & 2 & - & - & 2 \\
\hline s & 1 & 1 & $\uparrow$ & $f$ & $r$ & 1 \\
\hline s & $\gamma$ & $\gamma$ & $s$ & 8 & $\gamma B$ & B \\
\hline t & $t$ & $t$ & $t$ & $f_{0}$ & $t$ & $t$ \\
\hline u & $\stackrel{\partial}{a}$ & is & $\dot{u}$ & in & $\hat{n}$ & $\hat{u}$ \\
\hline$v$ & $\stackrel{0}{ }$ & $v$ & $\mathfrak{v}$ & $\infty$ & 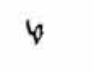 & $\mathfrak{D}$ \\
\hline w & Co & wo & ro & wa & wo & $w$ \\
\hline $\mathbf{x}$ & e & $\circlearrowright\}$ & $p x$ & - & - & - \\
\hline $\mathbf{y}$ & 9 & $y$ & $\mathfrak{y}$ & 3 & $y$ & $y$ \\
\hline z & $z$ & $\xi 3$ & $3\}$ & q & 3 & z \\
\hline
\end{tabular}




\begin{tabular}{|c|c|c|c|c|c|c|}
\hline \multicolumn{7}{|c|}{ II. } \\
\hline & 1 & 2 & 3 & 4 & 5 & 6 \\
\hline A & A $a$ & भ & $\oint$ & $a$ & $\mathcal{A}$ & A \\
\hline B & 3 & 8 & 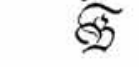 & bs & - & - \\
\hline C & c & $\varepsilon$ & Q & - & $\varepsilon \mathbb{C}$ & - \\
\hline D & 3 & F & (3) & $\theta$ & D & Sి \\
\hline E & (s) & $\mathfrak{E}$ & TE & $e$ & - & - \\
\hline F & $S$ & $\mathfrak{F}$ & 8 & - & $f$ & $\mathcal{S}$ \\
\hline G & $\mathfrak{S}$ & (B) & $\infty$ & $\mathfrak{B}$ & 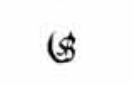 & \& \\
\hline H & $v$ & $\hat{2}$ & S3 & $b_{0}$ & - & $\sin$ \\
\hline I & $j$ & $\mathfrak{f}$ & द & I & 5 & - \\
\hline K & $\sqrt{k}$ & $\Re$ & तो & $k$ & - & $x$ \\
\hline $\mathbf{L}$ & $\alpha$ & $£$ & 2 & - & - & $\mathfrak{S}$ \\
\hline M & Sn & गfic & Ti & $m$ & - & $\sigma_{2}$ \\
\hline $\mathbf{N}$ & २ฉ & $\Re$ & कर & $M v$ & $x$ & - \\
\hline o & 0 & (2) & $\vartheta$ & $S$ & 2 & - \\
\hline$P$ & $P$ & $\mathfrak{B}$ & ड़्क & $p$ & $P$ & $\infty$ \\
\hline Q & $\{2$ & 2 & Q2 & - & - & - \\
\hline $\mathrm{R}$ & $R$ & $x \not{x}$ & ซ્s & - & $X R$ & $x$ \\
\hline $\mathbf{S}$ & $\gamma$ & $\mathfrak{S}$ & $\$$ & わ & $\$ \sigma$ & $\mathscr{B}$ \\
\hline $\mathrm{T}$ & $\tau$ & 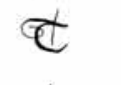 & ब्धु & $c$ & - & - \\
\hline $\mathrm{v}$ & $\mathfrak{i s}$ & का & GS? & - & - & $\mathfrak{B}$ \\
\hline W & 25 & 163 & PB & W & cos & $\mathfrak{W}$ \\
\hline $\mathrm{x}$ & $x$ & 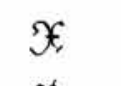 & जot & - & - & - \\
\hline Y & b & $\mathfrak{d}$ & (द्वी) & - & - & - \\
\hline z & 3 & 3 & है & $z$ & z & 3 \\
\hline
\end{tabular}




\section{Charakter pisma miejskiego skryby Heinricha Polana jako przykład zastosowania niemieckiego stylu neogotyckiego w urzędzie morawskiego miasta Olomuniec}

Streszczenie: Pośród miejskich skrybów pracujących w Ołomuńcu pomiędzy końcem lat trzydziestych i początkiem lat pięćdziesiątych XVI w. Heinricha Polana wyróżnia charakterystyczne pismo. Niniejsze studium poświęcone jest pismu tego autora, który należał do pokolenia ołomunieckich skrybów stosujących wyrazistą formę niemieckiego pisma neogotyckiego, wyróżniającą się wyjątkowym kątem pochylenia. Ta dominująca cecha jest łączona zwłaszcza z pracami norymberskiego mistrza Johanna Neudörffera Starszego. Artykuł dotyczy modelu paleograficznej analizy porównawczej pisma obu indywidualności. Na jej podstawie możemy stwierdzić, że charakter pisma Heinricha Polana i wzory listów Johanna Neudörffera łączy pewna liczba podobieństw, które przeważają nad różnicami w układzie pociągnięć piórem.

Heinrich Polan był Polakiem urodzonym w Gdańsku i spędził wiele lat w śląskiej Nysie. Jego przykład wskazuje na możliwy sposób przekazywania zaawansowanych neogotyckich form pisma ze Śląska na Morawy i stanowi przedmiot dalszych paleogeograficznych badań dotyczących niezgłębionego jeszcze tematu rozpowszechniania niemieckiego stylu neogotyckiego pomiędzy tymi dwoma obszarami. Istotę studium stanowi porównanie wybranego charakteru pisma ze współczesnym podręcznikowym stylem norymberskiej pisarskiej szkoły, w celu rozpoznania różnic i podobieństw. Może ono stać się fragmentem mozaiki obszernych badań i punktem wyjścia dalszych dociekań, które w pierwszej kolejności zbadają metody i dostępne opcje paleograficznej analizy pomocne w rozwiązaniu niniejszej kwestii.

\section{The handwriting of the town scribe Heinrich Polan as the application of the German neo-Gothic style in the office of the Moravian city Olomouc}

Summary: Among the Olomouc city scribes from the period from the late thirties to early fifties of the 16th century stands the writer Heinrich Polan out for its distinctive script. Our study is devoted to the written expression of this man. He belonged to the generation of Olomouc scribes with a clear form of the German neoGothic handwriting, that is already characterized by remarkable bond angle. Notably, this feature of the dominant angular bond joins Polans manuscript with the work of the Nuremberg Writing Master Johann Neudörffer Senior. This article deals with the paleographical comparative model analysis of the manuscripts both of these personalities.

Based on this analysis, we can conclude, that in the handwriting of Henry Polan and in the pattern of letters Johann Neudörffer there are a number of similarities outweighing the differences in the alignment of the pen strokes.

Heinrich Polan was a Pole, who was born in Danzig, after which he spent many years in the Silesian Nisa. Polan's example shows a possible way of transferring advanced neo-Gothic manuscript forms from Silesia to Moravia and serves as a subject for further paleogeographical research on the topic spread of German neoGothic handwriting between these areas, which have not yet been processed. The core of this case study consists in comparing the selected handwriting with the script of the contemporary textbook of the Nuremberg scribal school to determine their differences and compliance. However, it may become a small stone in the mosaic of extensive research and a starting point for further investigations, which first examines the methods and options paleographic analysis in resolving the issue. 
Nota o Autorze: B o h d a n K a ňá k jest od 1998 dyrektorem Powiatowego Archiwum Państwowego w Ołomuńcu. Niemal od początku swojej pracy w tej instytucji, od początku lat 90., gościnnie wykłada paleografię na Katedrze Historii Wydziału Filozoficznego Uniwersytetu Palackiego w Ołomuńcu. Do jego najważniejszych publikacji należą podręczniki paleografii i edycje źródłowe. Ponadto jego badania dotyczą historii Kościoła w Czechach, dziejów Ołomuńca, a także organizacja działalności zawodowej w dziedzinie archiwalnej.

Author: B ohdan K a ńák is since 1998 director of the State District Archive in Olomouc. Almost from the beginning of his operation in this institution, since the beginning of the $90 \mathrm{~s}$, he externally teaches palaeography at the Department of History, Philosophical Faculty of Palacký University in Olomouc. Paleographical textbooks and editions are also one of his most interesting professional works. In addition to this field is he interested in topics from the Czech ecclesiastical history, history of Olomouc as well as issues connected with the organization of professional activities in the archival field.

PhDr. Bohdan Kaňák, Ph.D.

Státní okresní archiv Olomouc

U Husova sboru 10

Olomouc

e-mail: b.kanak@archives.cz

\section{Quellen und Literatur}

Übersicht der Quellen

Neudörffer der Ältere, Johann: Ein gute ordnung und kurtze unterricht der furnemesten grunde, aus denen die jungen, zierlichs schreybens begirlich, mit besonderer kunst und behendigkeyt unterricht und geubt mögen werden ... 1538, Nürnberg

BSB München, AHAD, sign. Chalc. 18 a (VD16 N 563), fol. 40: <http://daten.digitale-sammlungen.de/ bsb00065307/image_85> fol. 27: <http://daten.digitale-sammlungen.de/bsb00065307/image_59> fol. 34: $<\mathrm{http} / / /$ daten.digitale-sammlungen.de/bsb00065307/image_73> fol. 10: $<\mathrm{http} / / /$ daten.digitale-sammlungen. de/bsb00065307/image_23> fol. 52: <http://daten.digitale-sammlungen.de/bsb00065307/image_109> [Zutritt: 12.02.2016]

Die Rechtsartikel des Olmützer städtischen Gerichts (Zusammen getragene artickel in form eines rechtlichen proces ... bei dieser ... stadt Olomuntz ... gehalten), 1550, SOkA Olomouc. AMO, Bücher, sign. 116, inv. č. 90.

Fugger, Wolfgang: Ein nutzlich und wolgegrundt formular, manncherley schöner schriefften, als teutscher, lateinischer, griechischer, unnd hebrayscher buchstaben, sampt unterrichtung, wie ein yede gebraucht werden ... 1553, Nürnberg

VKOl, [Vědecká knihovna v Olomouci — Die wissenschaftliche Bibliothek in Olmütz] Die historischen Sammlungen, sign. 602105.

Inventar der Verlassenschaften von den Stadtbürgern, (Inventarium), 1522-1564, SOkA Olomouc, AMO, Bücher, sign. 120, inv. č. 2017.

Das Zeugnisbuch vor dem anhängigen städtischen Gericht (Aussage der gefurtenn und producirten zeugen vor gehegter banckh ...), 1500-1579, SOkA Olomouc, AMO, Bücher, sign. 189, inv. č. 2046.

Die Rechtliche Hinweise und die Urteile von Breslau nach Olomouc gegeben 1484-1565, SOkA Olomouc, AMO, Bücher, sign. 6671, inv. č. 90a.

Das Gerichtsprotokoll der strittigen und unstrittigen Zivilangelegenheiten, 1528-1547, SOkA Olomouc, AMO, Bücher, sign. 1033, inv. č. 1658.

Das Gerichtsprotokoll der strittigen und unstrittigen Zivilangelegenheiten (Registrum ... iudicis), 1548-1549, SOkA Olomouc, AMO, Bücher, sign. 1046, inv. č. 1671.

Das Buch der Urteile des anhängigen städtischen Gerichts (Liber scabinorum ...), 1534-1554, SOkA Olomouc, AMO, Bücher, sign. 198, inv. č. 2037.

Übersicht der Literatur

Beck, Friedrich, Zur Herausbildung der deutschen Schreibschrift, insbesondere ihrer kursiven Formen, im Gebiet ostdeutscher Territorialstaaten im 16. Jahrhundert, in: „Jahrbuch für Geschichte der Feudalismus” 7, 1983, S. 265-286.

Bobowski, Kazimierz, Ewolucja pisma neogotyckiego na Ślasku od początku XVI do polowy XX wieku, Wrocław-Warszawa 1992. 
Bobowski, Kazimierz, Możliwości rozszerzania zakresu badań paleograficznych, in: Tradycje i perspektywy nauk pomocniczych historii w Polsce, Kraków 1995, S. 143-147.

Čáda, František, Polský rodák a městské právo v Olomouci a v Opavě, in: „Česko-polský sborník” 1, 1955, S. 270-292.

Doede, Werner, Bibliographie deutscher Schreibmeisterbücher von Neudörffer bis 1800, Hamburg 1961.

Doede, Werner, Schön schreiben, eine Kunst. Johann Neudörffer und seine Schule im 16. und 17. Jahrhundert, München 1957.

Dülfer, Kurt, Korn, Hans-Enno, Schrifttafeln zur deutschen Paläographie des 16.-20. Jahrhunderts, bearbeitet von Uhde, Karsten. Marburg ${ }^{10} 1998$.

Ebelová, Ivana, Klič k novověké paleografii. Schlüssel zur neuzeitlichen Paläographie, Praha 2004.

Ebelová, Ivana, Kašpar, Jaroslav, Hledíková, Zdeňka, Paleografická čítanka. Praha 2000.

Fischel, Alfred, Die Olmützer Gerichtsordnung. Ein Beitrag zur Geschichte des österreichischen Prozessrechtes, Brünn 1903.

Gieysztor, Aleksander, Zarys dziejow pisma lacińskiego, Warszawa 1973.

Górski, Karol, Neografia gotycka. Podręcznik pisma neogotyckiego XVI-XX w., Warszawa ${ }^{3} 1978$.

Hlaváček, Ivan, Kašpar, Jaroslav, Nový, Rostislav, Vademecum pomocných věd historických, Praha ${ }^{32} 202$.

Hledíková, Zdeňka, Kašpar, Jaroslav, Ebelová, Ivana, Paleografická čitanka, Praha 2000.

Hlobil, Ivo, Petrů, Eduard: Humanismus a raná renesance na Moravě, Praha 1992.

Kaňák, Bohdan, Německá novogotická polokurziva (kanzlei) olomoucké městské kanceláré v 16.-19. století, in: „Ročenka Státního okresního archivu v Olomouci” 8, 1999, S. 45-87.

Kaňák, Bohdan, Paleografická edice opisu učebnice psaní pocházejícího z počátku 16. století z Olomouce, Olomouc 2008.

Kaňák, Bohdan, Tajemství olomouckých městských knih, Olomouc 2014.

Kapr, Albert, Johann Neudörffer der Ältere, der grosse Schreibmeister der deutschen Renaissance, Leipzig 1956.

Kašpar, Jaroslav, $K$ problematice vzniku a vývoje německé novogotické kurzívy. (Na okraj studií Tamary N. Tacenkové a Friedricha Becka), in: AUC-PhilosHist 2. Z pomocných véd historických VIII, Praha 1988, S. $119-131$.

Kašpar, Jaroslav, Názvosloví novověkých písem, in: Kašpar, Jaroslav: Soubor statí o novověkém písmu, Praha 1993, S. 59-98.

Kašpar, Jaroslav, Norimberská písařská škola Johanna Neudörffera staršího a její vliv v českých zemích, in: Historia docet. Sborník prací k poctě 60. Narozenin prof. PhDr. Ivana Hlaváčka, Praha 1992, S. 135-144.

Kašpar, Jaroslav, Novogotické písmo v Čechách v letech 1500-1750, in: AUC-PhilosHist. 3-4, 1971, S. 111-159.

Kašpar, Jaroslav, Př́spěvek k metodice výzkumu novověkého psaného písma v Čechách. Problematika evidence psaného písma, AUC-PhilosHist. 5, 1980, Z pomocných věd historických IV, S. 69-82.

Kašpar, Jaroslav, Učebnice psaní Christofa Lindenspergera z počátku šestnáctého století, in: AUC-PhilosHist 1, Z pomocných věd historických III, Praha 1975, S. 105-116.

Kašpar, Jaroslav, Úvaha o paleografické terminologii, AUC-PhilosHist. 4-5, 1987, Z pomocných věd historických VI-VII, S. 9-33.

Kašpar, Jaroslav, Úvod do novověké latinské paleografie se zvláštním žretelem k českým zemím. 1. svazekTextová část, Praha ${ }^{3} 1987$.

Kašpar, Jaroslav, Hledíková, Zdeňka, Ebelová, Ivana, Paleografická čítanka, Praha 2000.

Kašpar, Jaroslav, Hlaváček, Ivan, Nový, Rostislav, Vademecum pomocných věd historických, Praha ${ }^{3} 2002$.

Korn, Hans-Enno, Dülfer, Kurt, Schrifttafeln zur deutschen Paläographie des 16. - 20. Jahrhunderts, bearbeitet von Uhde, Karsten. Marburg ${ }^{10} 1998$.

Kroman, Erik, Skriftens Historie i Danmark fra Reformationen til Nutiden, Kobenhavn 1943, ${ }^{2}$ Viborg 1964.

Kux, Johann, Verwaltungsgeschichte der Stadt Olmütz, Olmütz 1942.

Nešpor, Václav, Dějiny Olomouce, Brno 1936.

Nový, Rostislav, Hlaváček, Ivan, Kašpar, Jaroslav, Vademecum pomocných věd historických, Praha ${ }^{3} 2002$.

Od gotiky k renesanci. Výtvarná kultura Moravy a Slezska 1400-1550. III. Olomoucko, (Red.) Hlobil, Ivo, Perůtka, Marek, Olomouc 1999.

Petrů, Eduard, Hlobil, Ivo, Humanismus a raná renesance na Moravě, Praha 1992.

Radlinský, Miloš (Das Pseudonym von Prasek, Vinzenz), Vynikající osoby opavské z 16. století, in: „Věstník Matice opavské" 4, 1894, S. 25-29. 
Santifaller, Leo, Bozner Schreibschriften der Neuzeit 1500-1851. Beiträge zur Paläographie, Jena 1930.

Schneider, Karin, Paläographie - Handschriftenkunde, Tübingen 1999.

Schulz, Jindřich und andere, Dějiny Olomouce, 1. svazek, Olomouc, Statutární město Olomouc a Univerzita Palackého v Olomouci, 2009.

Schulz, Jindřich und andere, Olomouc. Malé dějiny města, Olomouc 2002.

Słowiński, Jan, Rozwój pisma łacińskiego w Polsce XVI-XVIII wieku, Lublin 1992.

Spáčil, Vladimír, Písaři a kanceláře města Olomouce do roku 1786, Olomouc 2001.

Spáčil, Vladimír, Sbírka listin archivu města Olomouce 1261-1793. Inventář, Olomouc 1998.

Zukal, Josef, Polanové z Polansdorfu. Památná rodina opavská 16. věku, ČMM 51, 1927, S. 99-123. 